OPEN ACCESS

Edited by:

Sara Eyal,

Hebrew University of Jerusalem, Israel

Reviewed by:

Yuqi Yang,

St. John's University, United States

Andrew Bahn,

University of Otago, New Zealand

*Correspondence:

Reina Bendayan r.bendayan@utoronto.ca

Specialty section:

This article was submitted to Drug Metabolism and Transport,

a section of the journal

Frontiers in Pharmacology

Received: 19 May 2021

Accepted: 26 July 2021

Published: 04 August 2021

Citation:

Whyte-Allman S-K, Kaul $R$ and Bendayan $R$ (2021) Regulation of $A B C$ Drug Efflux Transporters in Human $T$ Cells Exposed to an HIV Pseudotype.

Front. Pharmacol. 12:711999.

doi: 10.3389/fphar.2021.711999

\section{Regulation of $A B C$ Drug Efflux Transporters in Human T-Cells Exposed to an HIV Pseudotype}

\author{
Sana-Kay Whyte-Allman ${ }^{1}$, Rupert Kaul ${ }^{2}$ and Reina Bendayan ${ }^{1 *}$ \\ ${ }^{1}$ Department of Pharmaceutical Sciences, Leslie Dan Faculty of Pharmacy, University of Toronto, Toronto, ON, Canada, \\ ${ }^{2}$ Department of Immunology, Faculty of Medicine, University of Toronto, Toronto, ON, Canada
}

ATP-binding cassette (ABC) drug efflux transporters could contribute to low intracellular concentrations of antiretroviral drugs in HIV-1 cell reservoirs and sanctuary sites. Furthermore, the functional expression of these transporters could be induced in activated T-cells. Therefore, we investigated the expression of ABC drug efflux transporters in human T-cells exposed to an HIV pseudotype virus (pHIV $\mathrm{NL4-3}_{3}$ ), and further examined the potential involvement of the mammalian target of rapamycin (mTOR) signaling pathway in regulating their expression following exposure to $p H I V_{N L 4-3}$. Additionally, we investigated the contribution of the drug efflux transporters to the inflammatory response following $\mathrm{pHIV} \mathrm{N}_{\text {NL4-3 }}$-induced T-cell activation. Human peripheral blood mononuclear cells (PBMCs) were exposed to HIV-1 envelope glycoprotein gp120 IIIB, $\mathrm{pHIV} \mathrm{NL4-3}_{\mathrm{N}}$ and/or mTOR inhibitors. The expression of ABC transporters, T-cell activation marker CD69, mTOR and pHIV $\mathrm{NL4-3}_{3}$ was assessed in $\mathrm{CD}^{+}{ }^{+}$T-cells by Flow cytometry. mRNA and protein levels of proinflammatory cytokines (IL6, TNFa and INF $\gamma$ ) were examined in PBMCs by qPCR and ELISA analyses, respectively, following exposure to pHIV $\mathrm{NL4-3}_{3}$ with or without inhibitors of mTOR or ABC transporters. The expression of $A B C$ transporters (P-glycoprotein, breast cancer resistance protein and multi-drug resistance associated protein-1) was significantly increased in $\mathrm{CD}^{+}{ }^{+} \mathrm{T}$-cells exposed to $\mathrm{pHIV}$ NL4-3. Treatment with mTOR inhibitors attenuated $\mathrm{pHIV}_{\mathrm{NL4-3}}$-induced transporter expression, as well as mRNA and protein levels of IL6, TNFa and INF $\gamma$. Additionally, inhibition of P-gp or MRP1 activity resulted in lower concentrations of proinflammatory cytokines in supernatants of PBMC exposed to $\mathrm{pHIV}_{\mathrm{NL4-3}}$. Herein we present novel data demonstrating that upregulation of $A B C$ drug efflux transporters could involve the mTOR signaling pathway in CD4 ${ }^{+}$T-cells exposed to an HIV pseudotype. These transporters could limit antiretroviral drug penetration in HIV target T-cells. Furthermore, ABC transporters could potentially contribute to HIV-associated proinflammatory cytokine secretion.

Keywords: ATP-binding cassette transporters, human immunodeficiency virus, mammalian target of rapamycin, proinflammatory cytokines, T-lymphocytes 


\section{INTRODUCTION}

A major hallmark of HIV infection and disease progression is the increased activation of both the adaptive and innate immune systems (Meier and Altfeld, 2007; Maartens et al., 2014). Indeed, there is evidence of residual inflammation and increased immune activation in most people living with HIV despite effective antiretroviral therapy (ART) (Maartens et al., 2014). One of the main driving forces for immune activation during infection is the interaction of HIV with the Toll-like receptors expressed on plasmacytoid dendritic cells, leading to the production of proinflammatory cytokines (Maartens et al., 2014). In addition, our group and others have demonstrated that interactions of the HIV envelope glycoprotein (gp120) with the chemokine receptors CXCR4 and CCR 5 on cells such as brain macrophages and astrocytes, can induce the secretion of several proinflammatory cytokines such as TNF- $\alpha$, IL- $1 \beta$, and IL-6 (Koller et al., 2002; Lee et al., 2003; Ronaldson and Bendayan, 2006; Ronaldson et al., 2010; Ashraf et al., 2014a; Omeragic et al., 2017). Persistent immune activation then facilitates viral infection of activated $\mathrm{CD}^{+}{ }^{+} \mathrm{T}$-cells, the preferential targets for HIV-1 production, and may lead to the persistence of HIV within tissue reservoirs (Meier and Altfeld, 2007; Biancotto et al., 2008; Catalfamo et al., 2011).

The expression of several ATP-Binding Cassette (ABC) drug efflux transporters, including $\mathrm{P}$-glycoprotein (P-gp), breast cancer resistance protein (BCRP), and the multidrug resistance-associated protein-1 (MRP1), has been reported to correlate with T-cell activation (Zhang et al., 2006; Ebert et al., 2016). Particularly, Ebert et al., reported that increased expression of P-gp, MRP1 and BCRP correlated with increased expression of the T-cell activation marker CD69 in cells obtained from patients with myeloproliferative neoplasms (Ebert et al., 2016). Additionally, Gupta et al. demonstrated that activation of human T-cells with phytohemagglutinin (PHA), a selective T-cell mitogen, led to an amplification of P-gp expression at the mRNA and protein levels in these cells (Gupta et al., 1992). Furthermore, Liptrott et al. demonstrated increased expression of $A B C B 1 / \mathrm{P}$-gp, $A B C C 1 / \mathrm{MRP} 1$, and $A B C C 2 / \mathrm{MRP} 2 \mathrm{mRNA}$ and proteins, as well as reduced accumulation of digoxin and saquinavir, established substrates of $\mathrm{ABC}$ transporters, in peripheral blood mononuclear cells (PBMCs) in response to treatment with cytokines such as IL-2 and IFN- $\gamma$ (Liptrott et al., 2008). On the other hand, studies have also demonstrated that P-gp and MRP1 could participate in the secretion of cytokines in activated PBMCs (Drach et al., 1996; Pawlik et al., 2005; Zhang et al., 2006). Inhibition of P-gp by verapamil (a known P-gp substrate and inhibitor) or anti-P-gp antibodies decreased the secretion of IL-2, IL-4, TNF-a and IFN-y in PHA activated lymphocytes (Drach et al., 1996; Pawlik et al., 2005). MRP1 is also known to be involved in the secretion of several cytokines and leukotrienes (van de Ven et al., 2009), as well as exports glutathione and glutathione disulfide (Ronaldson and Bendayan, 2008). In the context of HIV infection, studies investigating the expression and activity of $\mathrm{ABC}$ drug efflux transporters in leukocytes are very limited. HIV-1 infection has been shown to induce the expression and activity of P-gp in the efflux of zidovudine and daunorubicin in the H9 T-cell line and the U937 monocytic cell line (Gupta and Gollapudi, 1993). In addition, Zhang et al. demonstrated higher expression of BCRP in $\mathrm{CD}^{+}$and $\mathrm{CD}^{+}$T-cells obtained from people living with HIV-1 (both ART-treated and untreated) compared to healthy donors (Zhang et al., 2014). This implies that activated $\mathrm{CD}^{+}{ }^{+} \mathrm{T}$-cells, the preferential target for HIV infection and replication, may also express higher levels of transporters responsible for the efflux of many medications, including antiretroviral agents.

The molecular pathways governing the functional expression of $\mathrm{ABC}$ drug efflux transporters in activated T-cells is not clearly understood, but studies have indicated that the mammalian target of rapamycin (mTOR) pathway (Supplementary Figure S1) could be involved (Kuo et al., 2011; Wang et al., 2013; Chen et al., 2015). mTOR is a serine/threonine protein kinase which is central to metabolic control in eukaryotic cells. mTOR exists as two structurally distinct complexes in cells, mTOR complex 1 (mTORC1) and mTORC2, that mediate separate but overlapping cellular functions. mTOR also plays a role in regulating immune responses in T-cells and antigen-presenting cells. Moreover, mTOR activation, as a result of co-stimulatory signals and cytokine production, leads to full T-cell activation, characterized by the elevation of $\mathrm{Ca}^{2+}$ and CD69 (Delgoffe and Powell, 2009; Deng et al., 2016). The involvement of mTOR in regulating P-gp expression has been demonstrated in the context of cancer. Wang et al. demonstrated that siRNA mediated knock-down of mTOR resulted in the downregulation of P-gp expression in hepatocellular carcinoma cells (Wang et al., 2013). In addition, Chen et al. demonstrated that selective inhibition of mTOR by compound OSI-027 attenuated doxorubicin-induced overexpression of P-gp in hepatocellular carcinoma cells (Chen et al., 2015). Furthermore, Scherbakova et al. demonstrated that the mTORC1 inhibitor rapamycin downregulated the protein expression of P-gp, BCRP and MRP1 in several human tumor cell lines (Scherbakova et al., 2009). Together, these studies provide evidence that activation of the mTOR signaling pathway could potentially result in increased expression and function of $\mathrm{ABC}$ transporters in T-cells.

HIV-1 requires a constant supply of proteins, nucleotides, and energy in order to replicate and generate new virions. Therefore, it has been proposed that this virus may regulate pathways involved in the synthesis of biomolecules, such as mTOR (Kumar et al., 2017). HIV-1 infection can activate the mTOR signaling cascade through the $\mathrm{T}$-cell receptor after the binding of viral gp120 to the CD4 receptor, as well as through a mechanism mediated by viral transactivator of transcription (Tat) (Deng et al., 2016; Kumar et al., 2017). Therefore HIV-induced activation of the mTOR signaling pathway could potentially result in an increased functional expression of $A B C$ transporters in HIV-1 infected T-cells, and in turn this could then contribute to suboptimal antiretroviral drug (ARV) drug penetration within these infected T-cells (Janneh et al., 2005, 2007). Furthermore, these transporters have been implicated in the secretion of proinflammatory cytokines (Drach et al., 1996; Frank et al., 2001; Zhang et al., 2006) and could potentially contribute more broadly to the HIV-associated inflammatory response. In this study, we investigated the role of mTOR in 
regulating $\mathrm{ABC}$ drug efflux transporters in activated $\mathrm{T}$-cells following exposure to $\mathrm{HIV}$-gp120 or $\mathrm{HIV}_{\mathrm{NL4}-3}$ pseudotyped with the vesicular stomatitis virus glycoprotein (VSVG), as well as assessed the potential role of these transporters in mediating inflammatory cytokine secretion. While, the $\mathrm{HIV}_{\text {NL4-3 }}$ provirus (pNL4-3 GagzipGFP) lacks viral enzymes that are necessary to facilitate its replication cycle, thereby rendering it non-infectious, we anticipate that viral proteins such as Tat could impact the expression of the transporters in PBMCs or T-cells (Hayashi et al., 2005, 2006; Zhou et al., 2016). This study could identify potential mechanisms contributing to low drug penetration in HIV cell reservoirs and sanctuary sites, and persistent immune activation and/or inflammation.

\section{MATERIALS AND METHODS}

\section{Ethics Statement}

PBMCs were obtained from the blood of symptom-free donors in accordance with the research protocol (REB-12-378) approved by the Unity Health Toronto Research Ethics Board.

\section{Virus Preparation and Infectivity Assays}

The HIV proviral plasmid pNL4-3 GagzipGFP, as well as the pPAX2 packaging construct and VSVG expression vector were kindly provided by Dr. Alan Cochrane (Department of Molecular Genetics, University of Toronto, Toronto, ON, Canada). pNL4-3 GagzipGFP was generated by replacement of the nucleocapsid $(\mathrm{NC})$, protease $(\mathrm{PR})$ and reverse transcriptase (RT) coding regions of pNL4-3 with a leucine zipper sequence fused to enhanced green fluorescence protein (GFP) (Platt et al., 2015). Human embryonic kidney 293T (HEK293T) cells $\left(2.5 \times 10^{5}\right)$ were transfected with pNL4-3, pPAX2 packaging construct and VSVG expression vector using the polyethylenimine transfection protocol to generate $\mathrm{HIV}_{\mathrm{NL4}-3}-\mathrm{VSVG}$ pseudotyped virus $\left(\mathrm{pHIV}_{\mathrm{NL4}-3}\right)$. Viral supernatant was harvested $72 \mathrm{~h}$ posttransfection and stored at $-80^{\circ} \mathrm{C}$. To assess the infectivity of the virus, $0.5 \times 10^{6}$ HEK293T or $2 \times 10^{6}$ PBMCs were inoculated with serial dilutions $(200-1,000 \mu \mathrm{l})$ of the viral stock. Infection was initiated through spinoculation at $1,200 \times \mathrm{g}$ for $2 \mathrm{~h}$ (O'Doherty et al., 2000). Cells were collected and fixed $72 \mathrm{~h}$ after infection, and the expression of the enhanced green fluorescence protein (GFP) in cells was determined by flow cytometry. Cells carrying GFP-expressing virus was quantified using FlowJo v10 software. Cells were efficiently transduced with the virus resulting in approximately $90 \%$ of HEK293T cells, and up to $60 \%$ of PBMCs expressing GFP with the highest volume of viral stock (Supplementary Figure S2). The viral titer was calculated and a multiplicity of infection (MOI) of 0.1 was used in subsequent experiments.

\section{PBMC Stimulation and Treatment With gp120, pHIV $\mathrm{NL4-3}$ and/or Pharmacological Inhibitors}

Recombinant HIV envelope glycoprotein 120 (gp120 IIIB) was obtained from the NIH AIDS Reagent Program (Germantown,
$\mathrm{MD}$, United States). gp $120_{\text {IIIB }}$ is derived from an X4-tropic viral strain which has been shown to efficiently activate $\mathrm{CD} 4^{+} \mathrm{T}$-cells, in vitro (Doms and Moore, 2010; Islam et al., 2013). Studies have also demonstrated a strong preference of X4-tropic HIV strains to target T-cells in vitro compared to other PBMC subsets (Grivel et al., 2000; Woodham et al., 2016), thereby increasing the proportion of infected T-cells. PBMCs isolated from the blood of symptom-free donors were stored in liquid nitrogen vapour phase. These cells were thawed at $37^{\circ} \mathrm{C}$ and exposed to PHA, or PHA in combination with gp $120_{\text {IIIB }}$. Initially, cells were treated with $1-10 \mu \mathrm{g} / \mathrm{ml}$ PHA or $0.25-1 \mu \mathrm{g} / \mathrm{ml}$ gp $120{ }_{\text {-IIв }}$ for $24-72 \mathrm{~h}$ as previously described (Pawlik et al., 2005; Zimmermann et al., 2015). The concentrations of gp120 $0_{\text {IIIB }}(1 \mu \mathrm{g} / \mathrm{ml})$ and PHA $(2.5 \mu \mathrm{g} / \mathrm{ml})$ that yielded consistent results were then used for subsequent experiments. In addition, simultaneous changes in the expression of the three transporters following exposure to these agents was observed at $48 \mathrm{~h}$, as such, cells were collected for flow cytometry analyses after a $48 \mathrm{~h}$ treatment duration. For experiments with $\mathrm{pHIV}_{\mathrm{NL} 4-3}$, PBMCs were cultured in IL-2 media (complete RPMI containing $10 \mathrm{U} / \mathrm{ml} \mathrm{IL-2)} \mathrm{to} \mathrm{induce}$ cell proliferation. Following $72 \mathrm{~h}$ PHA stimulation, cells were exposed to $\mathrm{pHIV} \mathrm{NL4}_{\mathrm{NL}}$ at an MOI of 0.1 in the presence of the infection reagent polybrene $(8 \mu \mathrm{g} / \mathrm{ml})$; unexposed control cells contained polybrene without the virus. A heat-inactivated $\mathrm{pHIV}_{\mathrm{NL4-3}}$ control, obtained by heating at $57^{\circ} \mathrm{C}$ for $45 \mathrm{~min}$, was used as an additional negative control to demonstrate specificity of the viral response (Supplementary Figure S3). Infection was initiated through spinoculation at $1,200 \times \mathrm{g}$ for $2 \mathrm{~h}$. Cells were then incubated at $37^{\circ} \mathrm{C}$ for $48 \mathrm{~h}$ to determine the effects of the virus on $\mathrm{T}$-cell activation and transporter expression by flow cytometry. To investigate the involvement of the mTOR pathway, cells were treated with mTORC1 inhibitor rapamycin $(5 \mu \mathrm{M})$, mTORC2 inhibitor JR-AB2-011 $(50 \mu \mathrm{M})$, dual mTOR inhibitor OSI-027 $(25 \mu \mathrm{M})$ which inhibits both mTORC1 and mTORC2 (Bhagwat et al., 2011), or vehicle control (DMSO) for $48 \mathrm{~h}$ following spinoculation. Initial dose-response experiments were performed for each inhibitor to determine an appropriate concentration to use in the subsequent experiments. To assess the function of the transporters in proinflammatory cytokine export, cells were exposed to P-gp inhibitors verapamil or PSC833, MRP1 inhibitor MK571 or vehicle for $48 \mathrm{~h}$ following spinoculation with the virus. The cells were centrifuged prior to flow cytometry analyses, and supernatants were collected and stored at $-80^{\circ} \mathrm{C}$ for enzyme linked immunoabsorbant assay (ELISA).

\section{Flow Cytometry}

PBMCs were collected by centrifugation $48 \mathrm{~h}$ following exposure to $\mathrm{pHIV}_{\mathrm{NL4}-3}$ and/or drug treatment and stained extra-cellularly with fluorochrome-conjugated antibodies to detect surface receptors $\mathrm{CD} 3, \mathrm{CD} 4$ and $\mathrm{CD} 69$, in the presence of the Zombie aqua cell viability dye (Supplementary Table S1) to exclude dead cells. Cells were then fixed and permeabilized prior to intracellular staining of ABC transporters P-gp, BCRP and MRP1 and phosphorylated pmTOR (aa 2448) using the True Nuclear Transcription Factor permeabilization kit (BioLegend, San Diego, CA, United States) and manufacturer's protocol. Cells were acquired on a Beckman Coulter Cytoflex-S benchtop 
cytometer to assess the expression of CD69, $\mathrm{ABC}$ transporters, pmTOR and GFP in $\mathrm{CD}^{+} \mathrm{CD}^{+} \mathrm{T}$-cells. Fluorescence minus one (FMO) strategy was used to set the gates for positive events, as previously demonstrated (Whyte-Allman et al., 2020). Data analysis was performed using FlowJo v10 software and GraphPad prism 7.03. See Supplementary Table S1 for a list of fluorochrome-conjugated antibodies and suppliers used in these experiments.

\section{Enzyme Linked Immunoabsorbant Assay}

Single-analyte colorimetric sandwich ELISA kits (QIAGEN, Toronto, ON, Canada) for human IL-6, INF $\gamma$ and TNF- $\alpha$ were used to detect the secretion of these cytokines in cell culture supernatants of PBMCs exposed to $\mathrm{PHIV}_{\mathrm{NL4-3}}$ in the presence or absence of a vehicle (DMSO) control or one of the following inhibitors: the mTOR inhibitor OSI-027 $(25 \mu \mathrm{M})$, P-gp inhibitors verapamil $(10$ or $50 \mu \mathrm{M})$ or PSC833 $(5 \mu \mathrm{M})$, or the MRP1 inhibitor MK571 $(10,50$, or $100 \mu \mathrm{M})$. These are HIV-inducible cytokines known to be produced by T-cells, and have been shown to be transported by the efflux transporters in previous studies (Kedzierska and Crowe, 2001; Pawlik et al., 2005; Zhang et al., 2006; Freeman et al., 2016). The concentrations of these compounds were chosen based on previous studies by our group and others to inhibit their transport function in PBMCs without exerting toxic effects (Drach et al., 1996; Pawlik et al., 2005; Zhang et al., 2006; Whyte-Allman et al., 2020). The assays were performed according to the manufacturer's instructions. Standard curves were generated using appropriate antigen standards and absorbance was read at $450 \mathrm{~nm}$ and converted to $\mathrm{pg} / \mathrm{ml}$.

\section{Real-Time Quantitative Polymerase Chain Reaction}

Real-time quantitative Polymerase Chain Reaction (qPCR) was applied to determine the transcript levels of inflammatory cytokines as previously described by our group (WhyteAllman et al., 2017; Omeragic et al., 2019, 2020). Briefly, total RNA was extracted from cells using TRizol reagent. The concentration of RNA was quantified spectrophotometrically by measuring absorbance at $260 \mathrm{~nm}$. Extracted RNA (2000 ng) was treated with amplification grade DNase $\mathrm{I}(0.1 \mathrm{U} / \mathrm{ml})$ to remove contaminating genomic DNA. The high-capacity cDNA reverse transcriptase kit (Applied Biosystems, Waltham, MA, United States) was used to synthesize firststrand cDNA. Human primers using TaqMan technology were purchased from Life Technologies (Burlington, ON, Canada) for the following genes: TNFa (Hs00174128_m1), IL6 (Hs00174131_m1) and IFN $\gamma$ (Hs00989291_m1) and housekeeping gene glyceraldehyde 3-phosphate dehydrogenase (GAPDH; Hs02758991_g1). Expression levels were normalized to the housekeeping gene, GAPDH and compared to vehicle-treated control group using the comparative $\mathrm{C}_{\mathrm{T}}\left(\Delta \Delta \mathrm{C}_{\mathrm{T}}\right)$ method and expressed as fold expression $\left(2^{-\Delta \Delta \mathrm{CT}}\right)$ to assess the relative difference in mRNA expression for each gene. GAPDH levels in the PBMCs remained consistent between experiments.

\section{Statistical Analysis}

All experiments were performed in cells isolated from the blood of at least three adult human donors. Results are expressed as the mean \pm SEM. Comparison between groups was performed as appropriate by applying one-way ANOVA with Bonferroni's multiple comparisons test using GraphPad Prism 7.03 software (GraphPad Software Inc., San Diego, CA, United States); $p<0.05$ was considered statistically significant.

\section{RESULTS}

\section{HIV-gp120 Enhances T-Cell Activation and ABC Transporter Expression}

To investigate whether the viral envelope protein gp120 could enhance T-cell activation and transporter expression, PBMCs were exposed to PHA, gp120 $0_{\text {IIIB }}$ or PHA in combination with gp120 IIIB. The expression of the ABC transporters or the T-cell activation marker CD69 in CD4 T-cells was then quantified and compared among these treatment groups following flow cytometry analyses. During flow cytometry analyses, cells were examined for viability using the zombie aqua cell viability dye and gated based on their expression of the CD3, CD4, and CD69 T-cell surface markers (Figure 1A). T-cell activation was determined by the expression of the CD69 T-cell activation marker. The expression of P-gp, BCRP and MRP1 was then evaluated in $\mathrm{CD} 3{ }^{+} \mathrm{CD} 4^{+} \mathrm{CD} 69^{+} \mathrm{T}$-cells and normalized to their expression in $\mathrm{CD} 3^{+} \mathrm{CD} 4^{+} \mathrm{CD} 69^{-} \mathrm{T}$-cells. As expected, PHA treatment increased the surface expression of the T-cell activation marker CD69 (203\%) compared to untreated control cells, as well as ABC transporters P-gp (25\%), BCRP (23\%) and MRP1 (21\%; Figures 1B-D). Overall, the highest expression of CD69 (248\%), P-gp (41\%), BCRP (49\%) and MRP1 (39\%) was observed in cells that were exposed to PHA + gp120. Although a higher level of expression was observed in cells treated with PHA + gp120 compared to PHA alone, the differences between these two groups did not reach statistical significance, except for BCRP. Exposing unstimulated cells to gp120 alone did not alter the expression of the transporters or CD69, suggesting its preferential interaction with PHA-stimulated T-cells. Together, these results indicate subtle effects of gp120 in enhancing T-cell activation and transporter expression in activated T-cells.

\section{Induction of ABC Transporters in pHIV $\mathrm{NL4-3}_{\mathbf{N}}$ Activated $\mathrm{CD}^{+}{ }^{+} \mathrm{T}$-Cells}

Next, we investigated the effects of $\mathrm{pHIV}_{\mathrm{NL} 4-3}$ in inducing the expression of the transporters in the T-cells. The expression of P-gp, BCRP and MRP1 was evaluated in PHA-stimulated CD4 ${ }^{+}$ $\mathrm{T}$-cells that were exposed to $\mathrm{pHIV}_{\mathrm{NL} 4-3}$ for $48 \mathrm{~h}$ and compared to unexposed control cells. Cells expressing GFP were considered $\mathrm{pHIV}_{\mathrm{NL4-3}}$ exposed. The expression level of P-gp, BCRP and MRP1 was then evaluated and compared in CD69-GFP- (nonactivated, non-pHIV $\mathrm{NL4}_{3}$-exposed), CD69+GFP- (activated, non-pHIV $\mathrm{NL} 4-3_{3}$-exposed), or $\mathrm{CD} 69+\mathrm{GFP}+$ (activated, $\mathrm{pHIV}_{\mathrm{NL} 4-3}$-exposed) $\mathrm{CD}^{+}$T-cells (Figure 2). The results demonstrated that exposure to $\mathrm{pHIV}_{\mathrm{NL4}-3}$ (CD69+GFP+) 
A
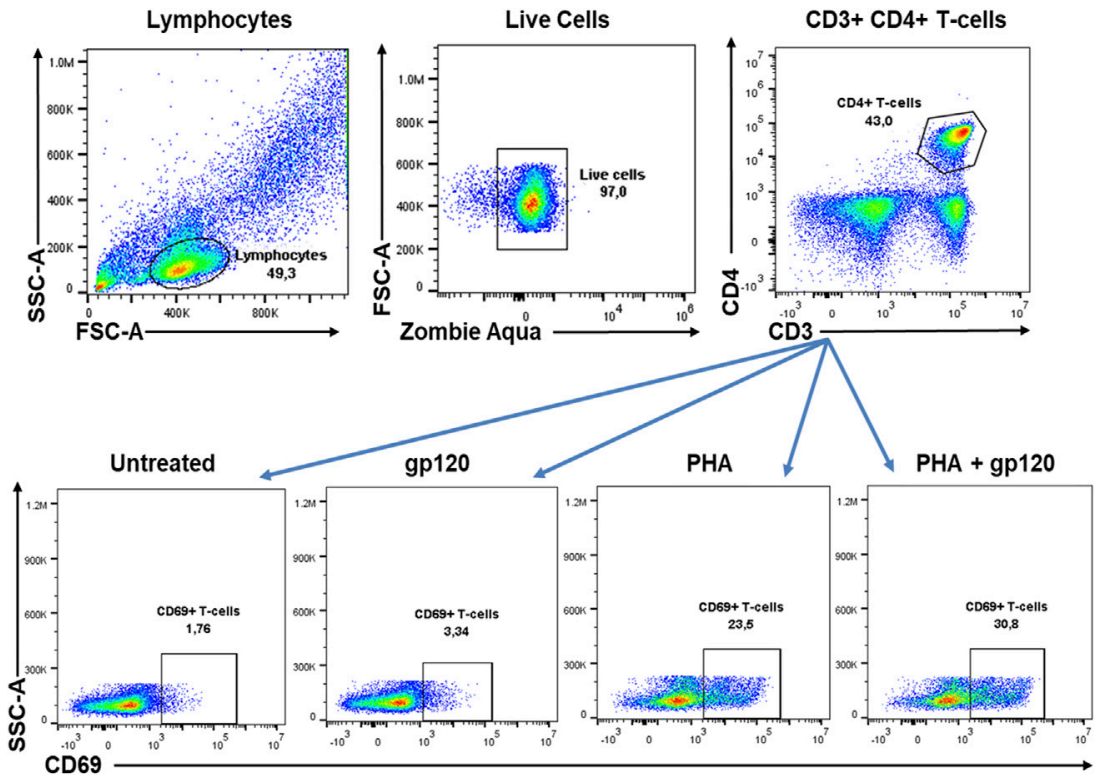

untreated

gp120

$\square$ PHA

PHA+ gp120
B

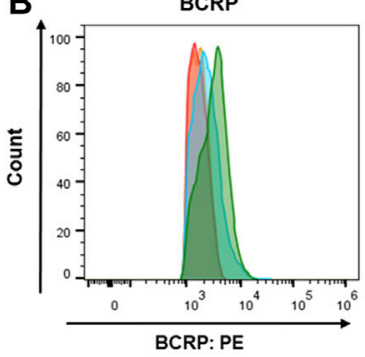

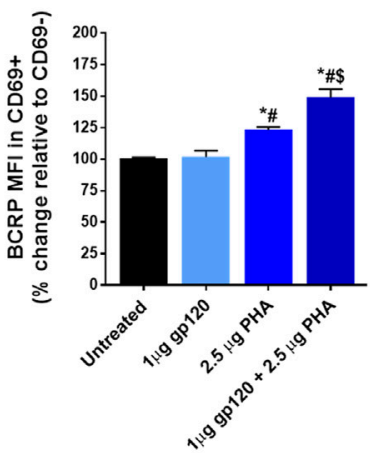

C
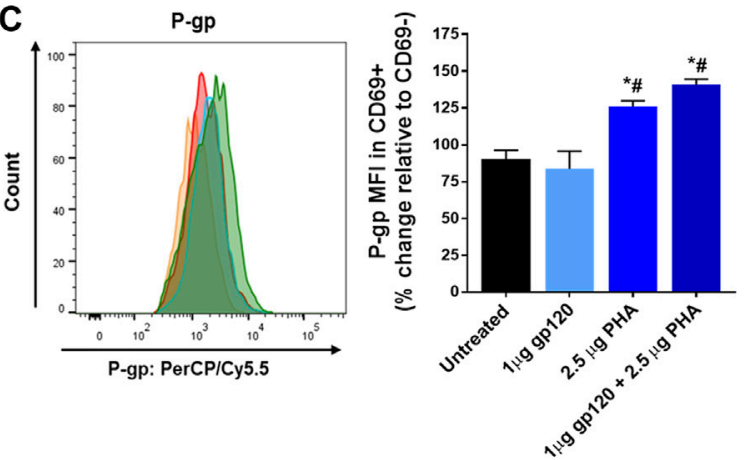

D
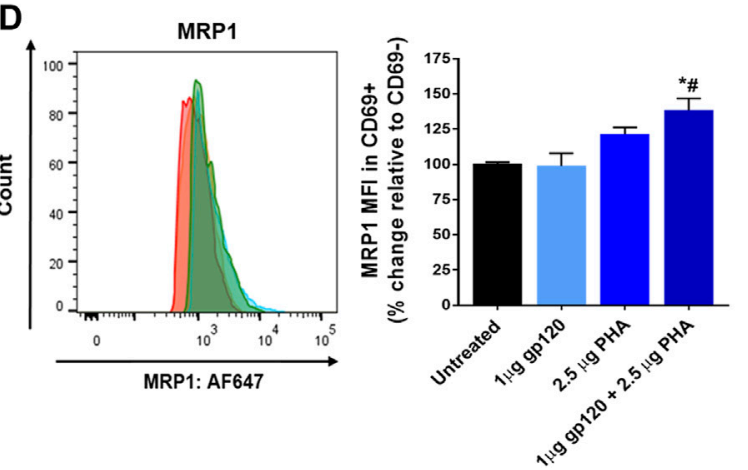

E

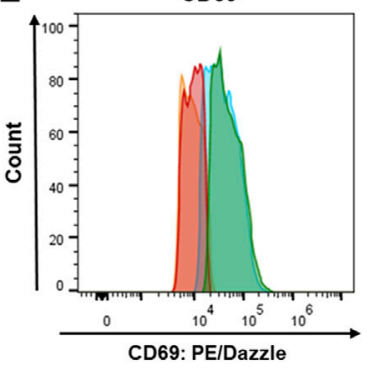

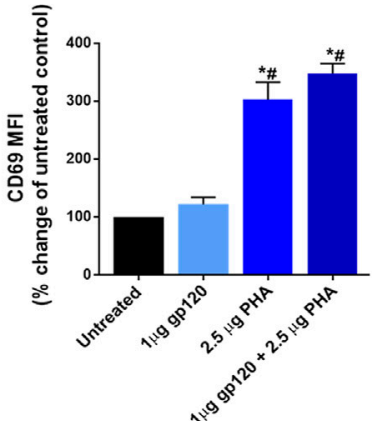

FIGURE 1 | Expression of BCRP, P-gp, MRP1 and CD69 in PHA and/or gp120 activated CD4+ T-cells. (A) Representative gating strategy for CD4 ${ }^{+}$T-cells isolated from PBMCs; panels from left to right show lymphocytes selected based on light scattering properties, viable (negative for Zombie Aqua) single cells were then selected for $\mathrm{CD}^{+}{ }^{+} \mathrm{CD} 4^{+}$expression, CD69 expression was determined in untreated, gp120 treated, PHA treated, or gp120 + PHA treated CD4 ${ }^{+}$T-cells. (B-D) Mean percent change \pm SEM of the expression (median fluorescence intensity, MFI) of each $\mathrm{ABC}$ transporter in $\mathrm{CD} 4^{+} \mathrm{CD} 69^{+} \mathrm{T}$-cells relative to their expression in non-activated CD4 ${ }^{+}$CD69- T-cells. (E) Mean percent change \pm SEM in the expression of CD69 in gp120 and/or PHA treated cells compared to untreated cells. Left panels show representative histograms corresponding to bar charts on the right (B-E). Statistical analyses were performed using one-way ANOVA with Bonferroni's multiple comparisons test, $p<0.05$. *, statistically significant difference compared to untreated control cells; \#, statistically significant difference compared to cells treated with gp120 only; $\$$, statistically significant difference compared to cells treated with PHA only, $n=3$ donors. 

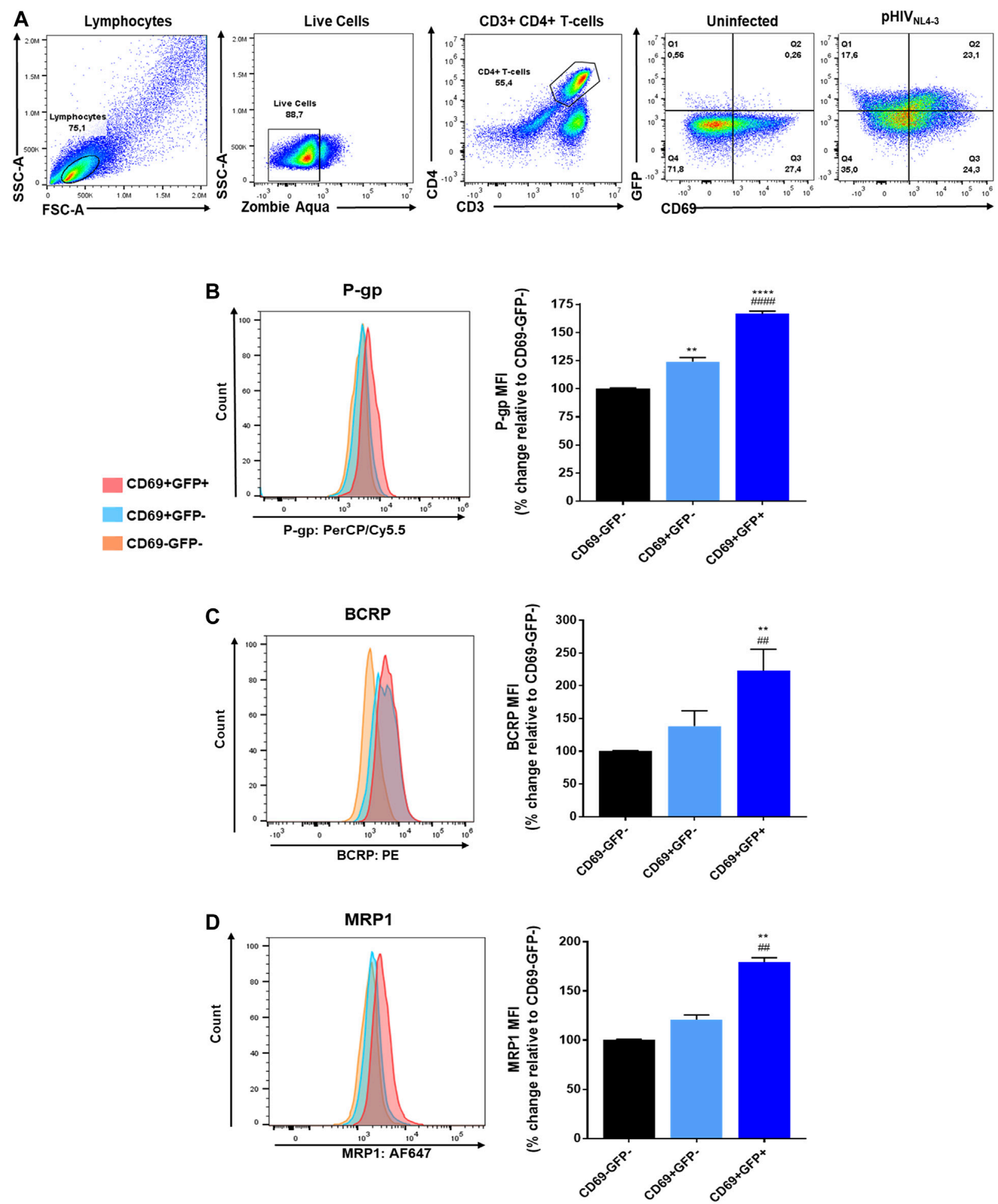

FIGURE 2 | Expression of P-gp, BCRP and MRP1 in pHIV $\mathrm{NL4-3}_{3}$ activated CD4+ T-cells. pHIV $\mathrm{NL4-3}_{3}$ in cells is demonstrated by the expression of GFP (GFP+). (A) Representative gating strategy for $\mathrm{CD}^{+} \mathrm{T}$-cells isolated from PBMCs exposed to $\mathrm{pHIV} \mathrm{V}_{\mathrm{NL4-3}}$ or untreated control; panels from left to right show lymphocytes selected based on light scattering properties, viable (negative for Zombie Aqua) single cells were then selected for $\mathrm{CD}^{+} \mathrm{CD}^{+}$expression, then the expression of $\mathrm{CD} 69$ and/or GFP was determined in $\mathrm{CD}^{+} \mathrm{T}$-cells. (B-D) Results are shown as mean percent change $\pm \mathrm{SEM}$ in the expression (median fluorescence intensity, MFI) of each ABC

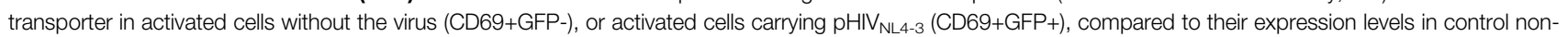
activated (CD69-GFP-) cells. Left panels show representative histograms corresponding to bar charts on the right. Statistical analyses were performed using one-way ANOVA with Bonferroni's multiple comparisons test. *, statistically significant difference compared to CD69-GFP- cells; \#, statistically significant difference compared to CD69+GFP- cells, $n=3$ donors. ${ }^{* \star}, p<0.01 ;{ }^{* \star \star *}, p<0.0001 ; \# \#, p<0.01 ; \# \# \#, p<0.0001$. 


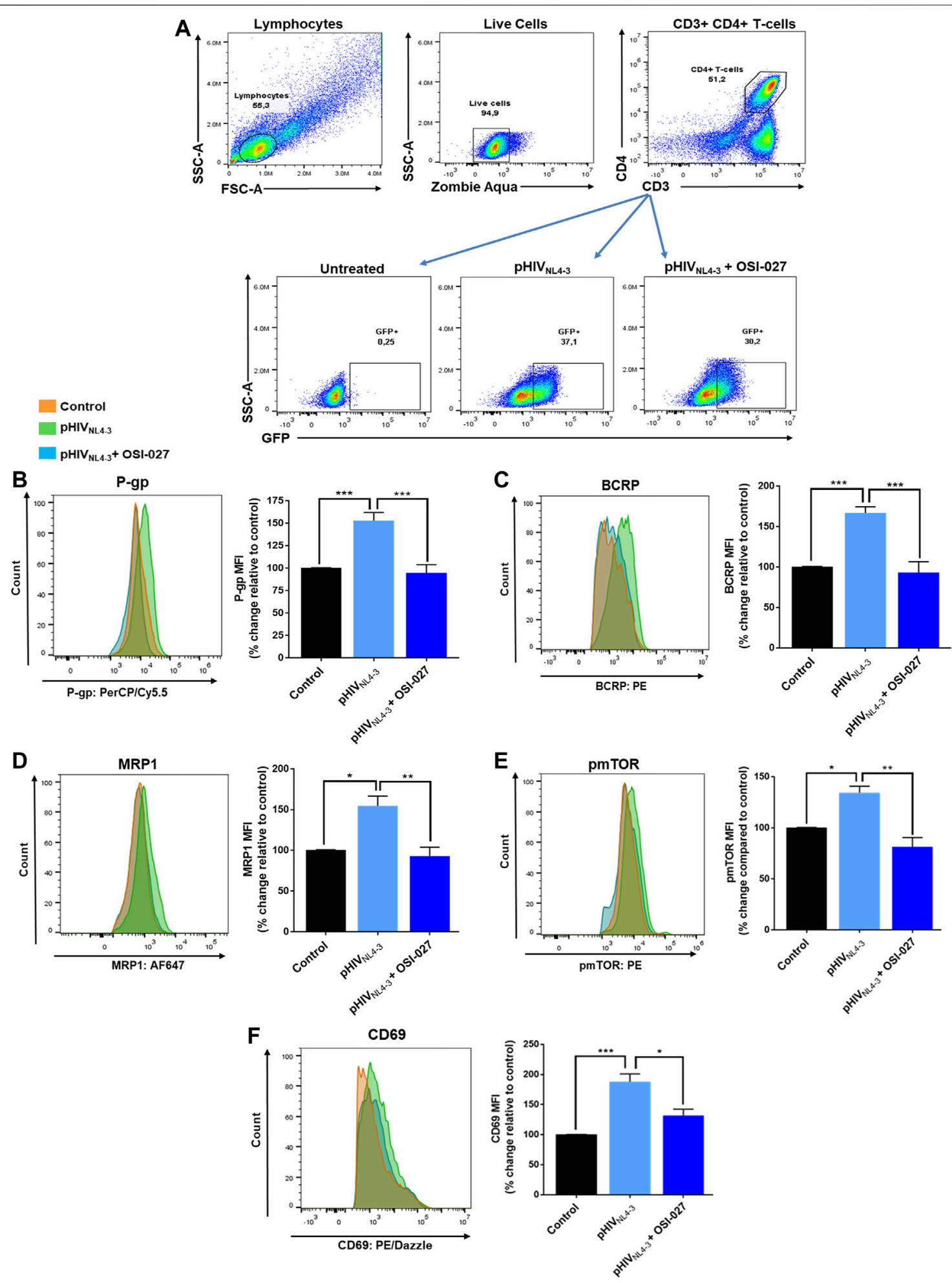

FIGURE 3 |mTOR inhibitor OSI-027 reverses $\mathrm{pHIV}_{\text {NL4-3 }}$-mediated induction of transporter expression. (A) Representative gating strategy for CD4 ${ }^{+} \mathrm{T}$-cells isolated from PBMCs; panels from left to right show lymphocytes selected based on light scattering properties, viable (negative for Zombie Aqua) single cells were then selected for $\mathrm{CD}^{+} \mathrm{CD}^{+}$expression. The expression of GFP is shown in untreated, pHIV $\mathrm{NLL-3}$ and/or OSI-027 $(25 \mu \mathrm{M})$ treated $\mathrm{CD} 4^{+}$T-cells after $48 \mathrm{~h}$ exposure. (B-F) Representative histograms (left) and corresponding bar charts (right) are shown. Results are shown as mean percent change \pm SEM in the expression (MFI) of P-gp (B), BCRP (C), MRP1 (D), pmTOR (E) and CD69 (F) in untreated (vehicle control), pHIV NL4-3, and/or OSI-027 treated CD4 ${ }^{+}$T-cells. Statistical analyses were performed using one-way ANOVA with Bonferroni's multiple comparisons test; $p<0.05$ was considered statistically significant, $n=3-4$ donors. *, $p<0.05$; ${ }^{* *}$, $p<0.01 ;{ }^{* \star \star}, p<0.001$. 


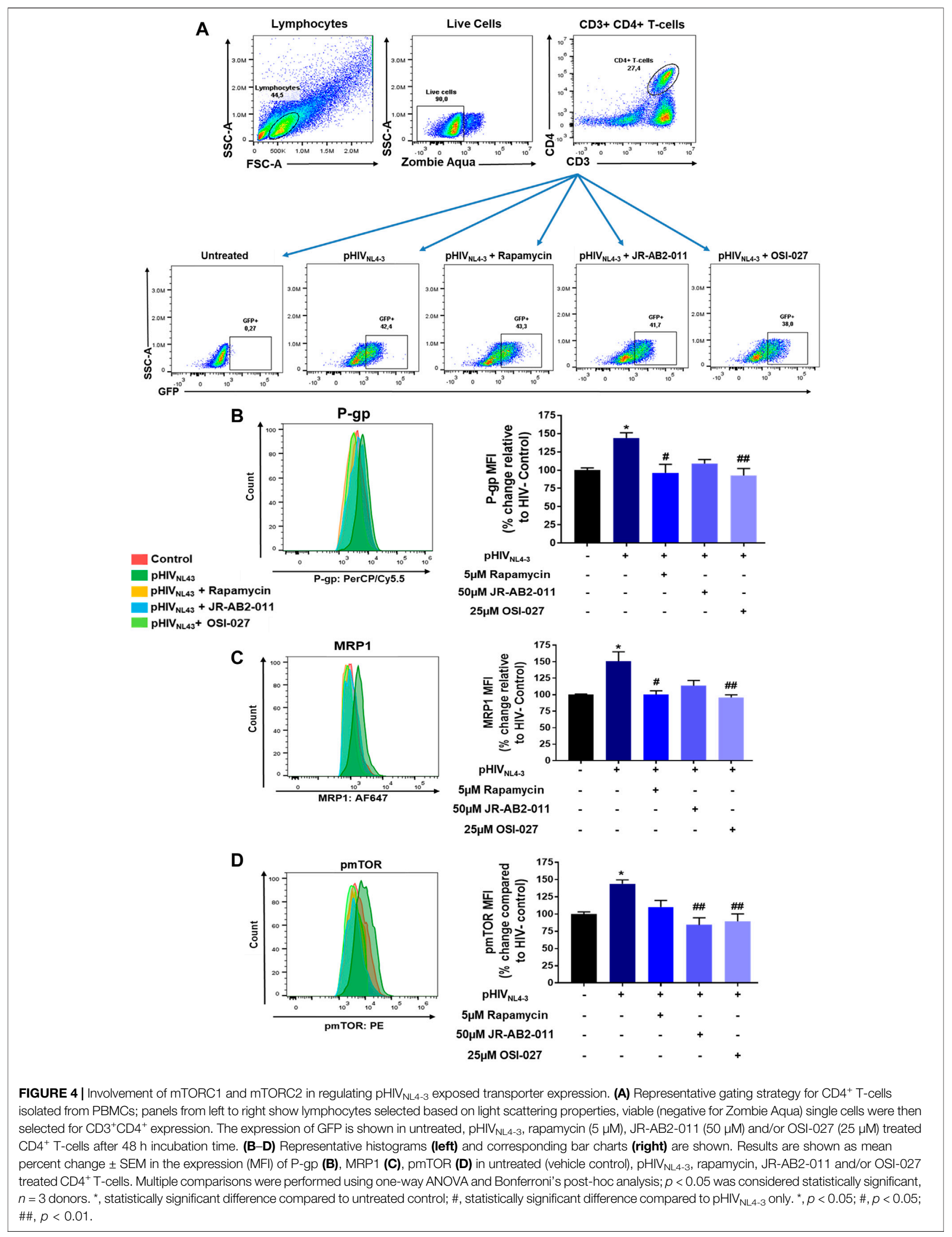


significantly enhanced P-gp, BCRP and MRP1 by 66, 123 and $80 \%$, respectively, when compared to CD69-GFP- cells (Figure 2). Their expression was also significantly higher in CD69+GFP+ compared to CD69+GFP- cells. These results suggest that HIV infection can induce $A B C$ drug efflux transporter expression in $\mathrm{CD} 4^{+} \mathrm{T}$-cells.

\section{Role of mTOR in CD4 ${ }^{+} \mathrm{T}$-Cell Activation and Induction of ABC Transporters in pHIV $\mathrm{NL4-3}$ Exposed CD4 ${ }^{+}$T-Cells}

To determine if the mTOR signaling pathway is involved in regulating the expression of $\mathrm{ABC}$ transporters in activated and/or pHIV $_{\text {NL4-3 }}$ exposed T-cells, the dual mTOR inhibitor OSI-027 was used to inhibit the phosphorylation and activity of mTOR (aa 2448) (Bhagwat et al., 2011). Following treatment, the expression of CD69, P-gp, BCRP, MRP1 and phosphorylated mTOR (pmTOR, aa 2448) was evaluated in $\mathrm{CD}^{+}{ }^{+} \mathrm{T}$-cells (Figure 3). OSI-027 had no significant effect on the percentage of cells carrying GFP-expressing virus (average frequencies of 32\% in $\mathrm{pHIV}_{\mathrm{NL4}-3}$ group vs. $30 \%$ in $\mathrm{pHIV}_{\mathrm{NL4}-3}+$ OSI-027 group, Figure 3A). Exposure to $\mathrm{pHIV}_{\mathrm{NL4}-3}$ induced the expression of P-gp (52\%), BCRP (66\%) and MRP1 (54\%), however, treatment with OSI-027 significantly reversed these effects, bringing the expression of these proteins to basal levels (Figures 3B-D). Exposure to $\mathrm{pHIV}_{\mathrm{NL4}-3}$ also induced activation of mTOR, resulting in increased pmTOR (34\%) expression. OSI-027 significantly decreased the levels of pmTOR following treatment (Figure 3E). Lastly, the expression of CD69 was also increased $(88 \%)$ in $\mathrm{pHIV}_{\mathrm{NL4-3}}$ exposed T-cells, suggesting enhanced T-cell activation. Inhibition of pmTOR with OSI-027 also reversed the $\mathrm{PHIV}_{\mathrm{NL} 4-3}$-induced $\mathrm{CD}^{+} \mathrm{T}$-cell activation, which was demonstrated by reduced levels of CD69 expression on these cells (Figure 3F). Overall, these results suggest a potential role of $\mathrm{mTOR}$ in regulating $\mathrm{T}$-cell activation and expression of $\mathrm{ABC}$ drug efflux transporters following exposure to $\mathrm{pHIV}_{\mathrm{NL} 4-3}$.

We further investigated the involvement of each mTOR subunit in the regulation of P-gp and MRP1 in $\mathrm{pHIV}_{\mathrm{NL4-3}}$ infected $\mathrm{CD}^{+}{ }^{+}$T-cells by selectively inhibiting mTORC1 with rapamycin (Wang et al., 2013) or mTORC2 with JR-AB2-011 (Benavides-Serrato et al., 2017) (Figure 4). Due to sample limitations, we only assessed the expression of P-gp, MRP1 and pmTOR in these experiments. The expression of these transport proteins in $\mathrm{CD}^{+}$T-cells was determined in each treatment group or control. Rapamycin treatment significantly decreased the expression of $\mathrm{pHIV}_{\mathrm{NL4}-3}$-induced P-gp and MRP1 by 40 and $43 \%$, respectively, while JR-AB2-011 significantly decreased the expression of pmTOR by $60 \%$. Although, rapamycin resulted in a $33 \%$ decrease in mTOR phosphorylation, this did not reach statistical significance. This is likely due to the small sample size. Overall, mTORC1 inhibition compared to mTORC2, was not found significantly different. However, mTOR inhibition with the dual inhibitor OSI-027 demonstrated significant effects in reversing the $\mathrm{pHIV}_{\mathrm{NL4-3}}{ }^{-}$ induced expression of these transporters. More work with a larger sample size is needed to further investigate the involvement of respective mTOR complexes in the regulation of these transporters following HIV infection.

\section{mTOR Regulates Proinflammatory Cytokine Production/Secretion Following Exposure to $\mathrm{pHIV}_{\mathrm{NL4-3}}$}

MTOR is known to play a role in modulating immune responses, therefore we evaluated the effects of mTOR inhibition on the production of proinflammatory cytokines following exposure to $\mathrm{pHIV}_{\mathrm{NL4-3}}$. Exposure of PBMCs to $\mathrm{pHIV}_{\mathrm{NL4}-3}$ induced a robust inflammatory response which resulted in elevated cellular mRNA levels and secreted protein concentrations of the proinflammatory cytokines TNFa, INF $\gamma$ and IL6 (Figure 5). Inhibiting the mTOR pathway with OSI-027 for $48 \mathrm{~h}$ significantly attenuated the $\mathrm{pHIV} \mathrm{V}_{\mathrm{NL4}}$ 3 -induced mRNA expression and extracellular protein concentrations of TNFa, INF $\gamma$ and IL6 in PBMCs. These results demonstrate an inflammatory response following exposure to $\mathrm{pHIV}_{\mathrm{NL4}-3}$ and confirm that mTOR plays a role in regulating proinflammatory cytokine production from activated T-cells as previously reported (HerreroSánchez et al., 2016).

\section{Involvement of P-gp and MRP1 in the Release of Proinflammatory Cytokines Following Exposure to pHIV $\mathrm{NL4-3}_{\mathrm{N}}$}

In the context of cancer or autoimmune disease, studies have demonstrated that drug efflux transporters such as P-gp and MRP1 could participate in the secretion of proinflammatory cytokines following activation of T-cells (Drach et al., 1996; Pawlik et al., 2005; Zhang et al., 2006). As these transporters are upregulated during $\mathrm{pHIV}_{\mathrm{NL} 4-3}$-induced T-cell activation, we further investigated their potential roles in the release of proinflammatory cytokines following exposure to the viral pseudotype. To examine the functional involvement of these transporters in the release of proinflammatory cytokines, PBMCs were treated with well-characterized transporter inhibitors following $\mathrm{pHIV}_{\mathrm{NL4-3}}$ exposure. Specifically, P-gp was inhibited with PSC833 and verapamil, while MK571 was used to inhibit MRP1. The results demonstrated elevated cytokine levels in the supernatants of cells exposed to $\mathrm{pHIV}_{\mathrm{NL} 4-3}$ when compared to uninfected control cells (Figure 6). Treating cells with P-gp or MRP1 inhibitors significantly decreased proinflammatory cytokine concentrations in the supernatants of cells exposed to $\mathrm{pHIV}_{\mathrm{NL4-3}}$. These data suggest that $\mathrm{ABC}$ transporters could potentially contribute to proinflammatory cytokine export from HIV-infected T-cells.

\section{mRNA Expression of Proinflammatory Cytokines Following Exposure to pHIV $\mathrm{NL4-3}$ and/or P-gp and MRP1 Inhibitors}

We further investigated if inhibiting P-gp or MRP1 affected the production of proinflammatory cytokines, rather than their export, by assessing their expression at the mRNA level following exposure to the transporter inhibitors. The corresponding mRNA expression of these cytokines was 


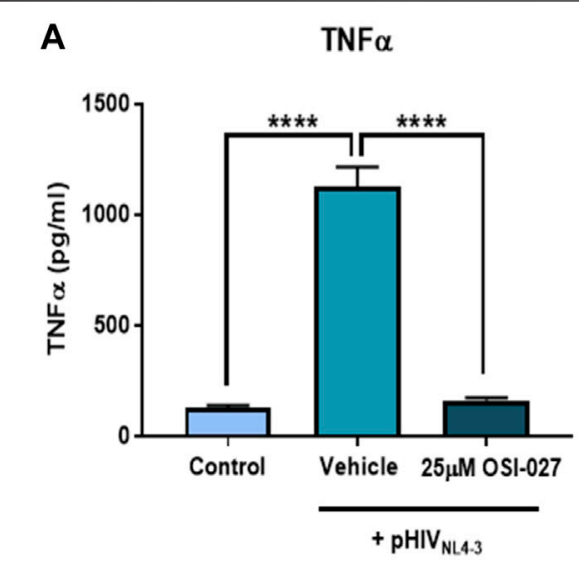

B

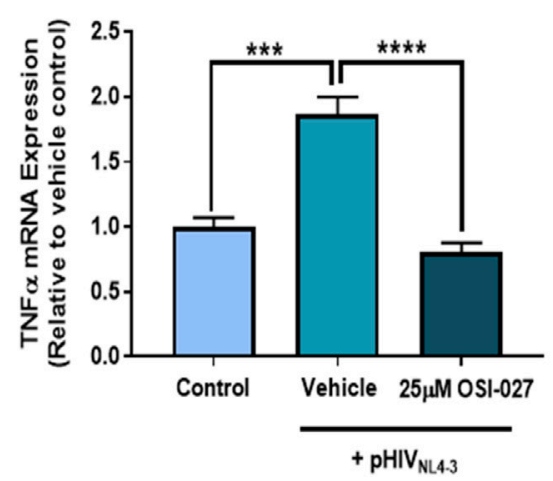

INF $\gamma$

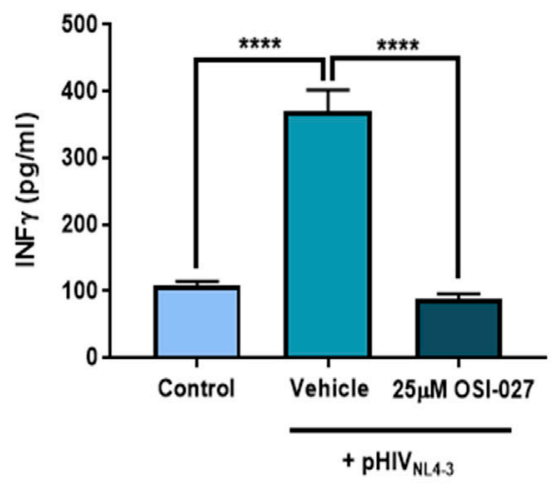

INF $\gamma$

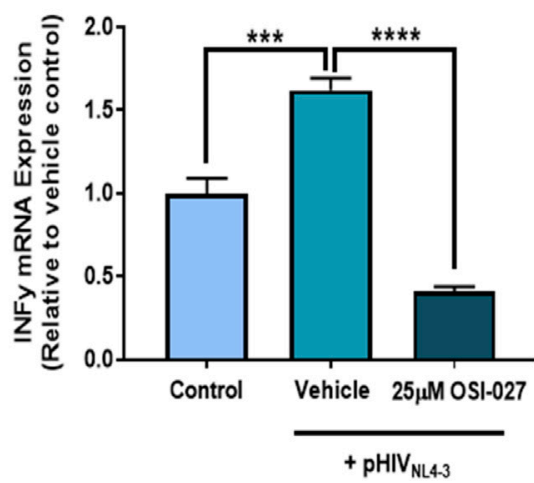

IL6

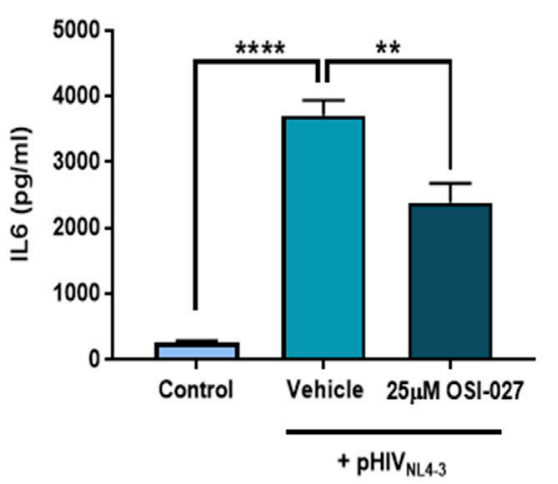

IL6

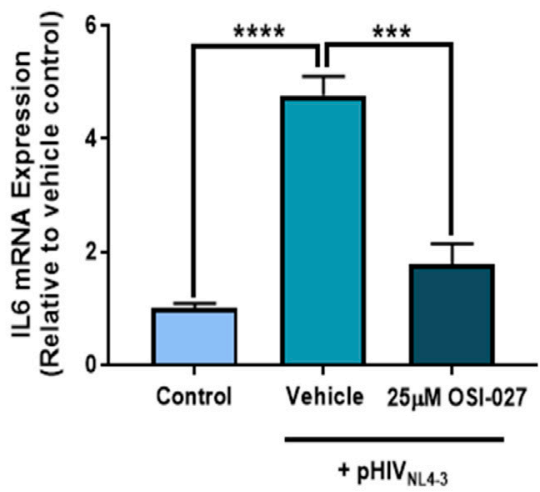

FIGURE 5 | The effects of mTOR inhibitor OSI-027 on the expression and secretion of proinflammatory cytokines from pHIV $\mathrm{NL4}_{3}$ exposed PBMCs. PBMCs and supernatants were collected following exposure to vehicle, pHIV $\mathrm{NL4-3}_{3}$ only, or pHIV $\mathrm{NL4-3}_{3}$ in the presence of $25 \mu \mathrm{M}$ OSI-027 for $48 \mathrm{~h}$. (A) cytokine concentrations in cell culture supernatants; results are expressed as mean \pm SEM ( $n=3$ donors). (B) Cytokine mRNA levels were measured using qPCR. GAPDH was used as the housekeeping gene. Results are expressed as mean $\pm \mathrm{SD}(n=3$ donors). Asterisks represent data points significantly different from cells exposed to HIV only. Multiple comparisons were performed using one-way ANOVA and Bonferroni's post-hoc analysis; $p<0.05$ was considered statistically significant. ${ }^{\star \star}, p<0.01 ;{ }^{\star \star \star}, p<$ $0.001 ;{ }^{* \star \star *}, p<0.0001$.

assessed in PBMCs exposed to $\mathrm{pHIV}_{\mathrm{NL4-3}}$ and treated with transporter inhibitors compared to cells exposed to the virus only or negative control (Figure 7). The results demonstrate significant increase in the mRNA expression of IL-6, TNFa, INF $\gamma$ in cells exposed to $\mathrm{pHIV}_{\mathrm{NL} 4-3}$. P-gp inhibitors verapamil and PSC833 did not alter the $\mathrm{pHIV} \mathrm{NL4}_{\mathrm{N}-3}$-induced mRNA expression of these cytokines. However, MRP1 inhibitor MK571 significantly attenuated $\mathrm{pHIV}_{\mathrm{NL4}-3}$-induced cytokine mRNA expression, suggesting its potential role in contributing to the transcriptional processes of these proinflammatory cytokines in the context of HIV infection. To the best of our knowledge this is the first study investigating the effects of these inhibitors on the mRNA expression of proinflammatory cytokines in the context of HIV infection.

\section{DISCUSSION}

It is well established that activation of $\mathrm{CD} 4^{+} \mathrm{T}$-cells enables their infection by HIV, and that the percentage of activated T-cells is increased in people with treated HIV infection (Biancotto et al., 2008; Catalfamo et al., 2011). The expression of ABC drug efflux transporters could also be increased in HIV-infected T-cells, however the mechanisms underlying their upregulation in these HIV cellular targets have not been investigated. Upregulation of $\mathrm{ABC}$ transporters in T-cells could potentially contribute to persistent infection by reducing ARV penetration in these cells, and possibly influencing HIV-associated inflammation. We previously demonstrated functional activity of these transporters in restricting the cellular permeability of their substrates in human T-cells (Whyte-Allman et al., 2020). However, in this study we investigated their expression and regulation by mTOR during $\mathrm{T}$-cell activation, as well as their functional roles in proinflammatory cytokine secretion, following exposure of PBMCs to HIV-gp120 or $\mathrm{pHIV}_{\mathrm{NL4}-3}$, an X4-tropic HIV strain pseudotyped with VSVG. Overall, our results demonstrated that $\mathrm{pHIV}_{\mathrm{NL4}-3}$ induced $\mathrm{T}$-cell activation and inflammatory response, resulting in the upregulation of P-gp, BCRP and MRP1 via the mTOR signaling pathway. These 


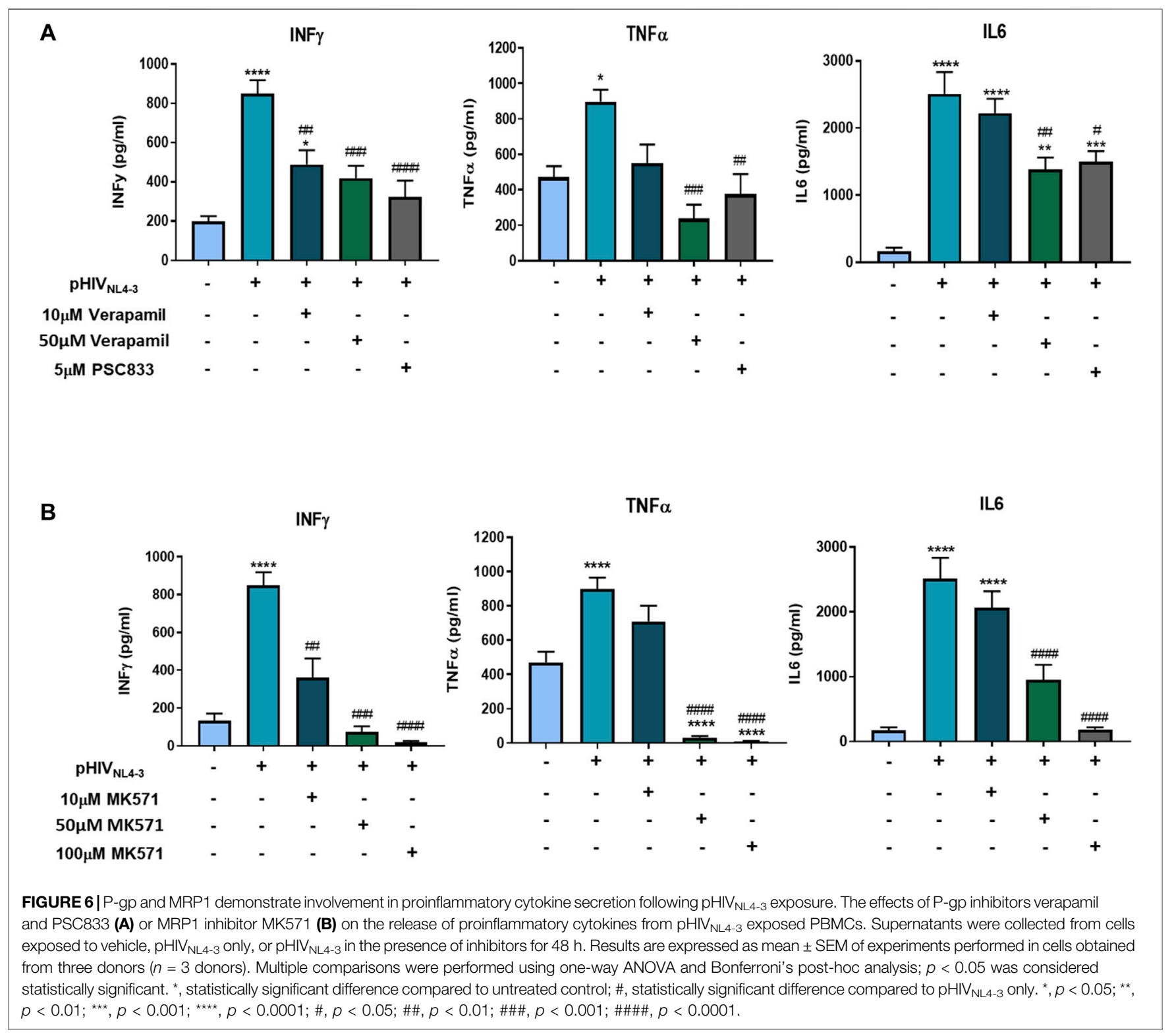

transporters also demonstrated a potential indirect role in the export of proinflammatory cytokines when PBMCs were exposed to $\mathrm{pHIV} \mathrm{V}_{\mathrm{NL} 4-3}$. Together, the data suggest that $\mathrm{ABC}$ transporters could contribute to sustained viral replication and/or reduced ARV intracelluar concentrations in cells known to form HIV reservoirs.

PBMCs were exposed to a concentration of gp120 IIIB (i.e., $1 \mu \mathrm{g} / \mathrm{ml}$ ) that is at the upper end of the reported plasma concentration range $(120-960 \mathrm{ng} / \mathrm{ml})$ for HIV-infected individuals (Cummins et al., 2010). Overall, significant increases in the expression of the efflux transporters P-gp, BCRP and MRP1, as well as the T-cell activation marker CD69, were observed when cells were treated with gp120 IIIB + PHA. However, the effects of this single viral protein were very mild, and in most cases did not reach significance, when compared to cells that were treated with PHA only. We then evaluated the effects of the HIV pseudotype, $\mathrm{pHIV}_{\mathrm{NL4-3}}$, on the expression of the drug efflux transporters P-gp, BCRP, MRP1 and CD69 and observed significant increases in their expression following exposure to the virus. Zhang et al. previously demonstrated that compared to HIV-negative donors, BCRP expression was higher in $\mathrm{CD}^{+}$and $\mathrm{CD}^{+} \mathrm{T}$-cells obtained from both ART-treated and ART-naïve individuals living with HIV (Zhang et al., 2014). In addition, higher mRNA expression of P-gp, MRP1, MRP4 and MRP5 was demonstrated in PBMCs isolated from individuals with HIV compared to control (Turriziani et al., 2008). Furthermore, a positive correlation between HIV-1 plasma viral load and P-gp activity in primary $\mathrm{CD}^{+}$and $\mathrm{CD}^{+} \mathrm{CD} 45 \mathrm{RA}$-memory T-cells was demonstrated (Minuesa et al., 2016). Our group and others also observed increased expression of $\mathrm{ABC}$ drug transporters in memory T-cells when compared to their naïve counterparts (Zhang 


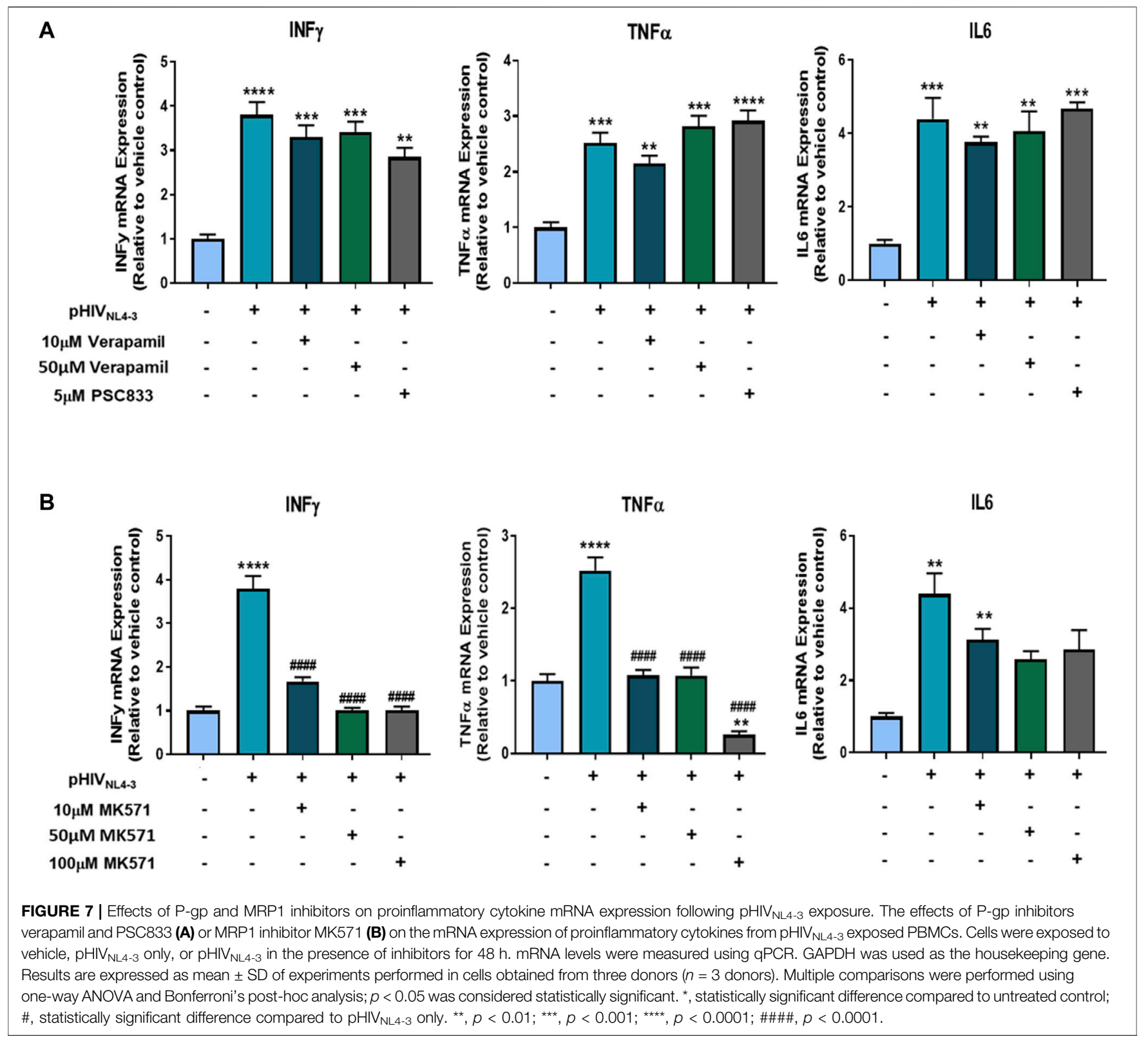

et al., 2006; Whyte-Allman et al., 2020), further suggesting that these transporters are induced in activated T-cells.

We identified the mTOR signaling pathway as a potential mechanism involved in the upregulation of $\mathrm{ABC}$ drug efflux transporters and CD69 in CD4 ${ }^{+}$T-cells exposed to $\mathrm{pHIV}_{\mathrm{NL} 4-3}$. HIV requires a constant supply of proteins, nucleotides and energy to maintain viral replication. Therefore it has been hypothesized that the virus induces pathways such as mTOR, which plays a major role in biosynthesis and metabolism (Kumar et al., 2017). Furthermore, Kumar et al. provided evidence that HIV activates mTOR in Jurkat cells (a latent T-cell model), HeLa cells, and peripheral blood lymphocytes (Kumar et al., 2017). Herein, treatment with the dual mTOR inhibitor OSI-027 attenuated the $\mathrm{pHIV}_{\mathrm{NL4}-3}$-induced expression of P-gp, BCRP, MRP1, CD69 and pmTOR. These results corroborate previous studies which demonstrated that gene silencing or selective inhibition of mTOR decreased the expression of transporters such as P-gp in the context of cancer (Pop et al., 2009; Wang et al., 2013; Chen et al., 2015). We sought to examine the involvement of each mTOR subunit in regulating P-gp and MRP1 expression in $\mathrm{pHIV}_{\mathrm{NL4-3}}$ exposed cells, by selectively inhibiting mTORC1 with rapamycin, or mTORC2 with the JR-AB2-011 compound. mTORC1-mediated phosphorylation of the downstream protein synthesis initiation factor 4E-Binding Protein 1 (4E-BP1) could result in the translation of proteins such as P-gp, see Supplementary Figure S1 (Wang et al., 2013), while mTORC2 has been implicated in the transcriptional regulation of this transporter (Kuo et al., 2002). While our results point towards a possible role of $\mathrm{mTORC} 1$ in regulating the protein expression of these transporters, we cannot definitively conclude 
that this subunit is majorly involved in the regulation of the transporters compared to mTORC2. Furthermore, we cannot rule out the involvement of $\mathrm{mTORC} 2$ in regulating the expression of these transporters following infection, since we did not assess their gene expression. To the best of our knowledge, this is the first study demonstrating that HIV-mediated activation of mTOR results in the induction of $\mathrm{ABC}$ drug efflux transporters. Overall, our results shed light on the mTOR pathway in regulating the expression of these transporters following exposure to $\mathrm{pHIV}_{\mathrm{NL} 4-3}$, however more work is needed with a larger sample size to further dissect the role of the mTOR subunits in this context.

We also demonstrated a role of $\mathrm{mTOR}$ in regulating the production of several proinflammatory cytokines following exposure to $\mathrm{pHIV} \mathrm{NL4-3}_{\mathrm{N}}$. In agreement with our data, previous work also showed that inhibition of mTOR prevented T-cell activation and significantly decreased the secretion of several proinflammatory cytokines, including IL-6, TNFa and INF $\gamma$, in isolated T-cells (Herrero-Sánchez et al., 2016). Activation of mTORC2 potentially leads to downstream activation of $\mathrm{NF \kappa B}$ (Kuo et al., 2002), a transcription factor known to promote the production of proinflammatory cytokines (Ronaldson and Bendayan, 2006; Ashraf et al., 2014b). Moreover, Wei et al. demonstrated that siRNA gene silencing and/or pharmacologic inhibition of the mTORC2 signaling pathway resulted in inhibition of LPS-induced NFKB phosphorylation and activation, and subsequently the production of proinflammatory cytokines IL-12, IL-23, INF $\gamma$ and IL-17 in dendritic cells or T-cells cocultured with dendritic cells (Wei et al., 2015).

In classical secretory pathways, cytokines are loaded into membrane-bound vesicles, granules, or both, and delivered to the cell surface for release. However, various non-classical mechanisms are proposed for cytokines crossing the plasma membrane, including the use of membrane transporters, microvesicle shedding, or cell lysis (Nickel, 2003; Lacy and Stow, 2011). ABC drug efflux transporters have been implicated in the export of proinflammatory cytokines following activation of immune cells, but it remains controversial as to whether these transporters are involved in a non-classical membrane trafficking process as suggested by some groups (Drach et al., 1996; Zhang et al., 2006), or whether they mediate the secretion of other relevant physiological substrates, such as bioactive lipids, which in turn result in cytokine secretion as a secondary effect (Huang et al., 1999; Raggers et al., 2001). We detected significant and robust increases in proinflammatory cytokines IL6, TNFa and INF $\gamma$ concentrations following exposure to $\mathrm{pHIV}_{\mathrm{NL4-3}}$. However, inhibiting the function of P-gp and MRP1 significantly decreased the concentrations of these cytokines, demonstrating the potential roles of these transporters in cytokine export. These results are consistent with previous studies demonstrating that P-gp and MRP1 are involved in the transport of these cytokines in activated PBMCs or purified CD4 ${ }^{+}$T-cells (Drach et al., 1996; Frank et al., 2001; Pawlik et al., 2005; Zhang et al., 2006). At the mRNA level, inhibition of P-gp did not affect cytokine expression, suggesting that this transporter is only involved in the export of these cytokines. On the other hand, the MRP1 inhibitor MK571 attenuated the mRNA expression of these cytokines. It was previously proposed that MRP1 inhibition with MK571 led to higher intracellular accumulation of an eicosanoid substrate which, in turn, activated the transcriptional repressor peroxisome proliferator-activated receptor- $\gamma(\operatorname{PPAR} \gamma)$, resulting in decreased cytokine production (Zhang et al., 2006). However, future studies are needed to investigate the effect of MK571 on PPAR $\gamma$ mediated cytokine reduction following HIV infection. In addition, at high concentrations MK571 could inhibit the function of MRP2 and MRP4, transporters that are also implicated in the export of various inflammatory mediators (van de Ven et al., 2009). Overall, these data suggest that MRP inhibition may indirectly reduce the production of proinflammatory cytokines, as well their export. While further work is needed, the current findings suggest an indirect role of $\mathrm{ABC}$ transporters in sustaining persistent HIV infection by contributing to proinflammatory cytokine release. The extent at which these transporters participate in inflammatory processes in people living with HIV necessitates further investigation.

A limitation of this study is that exposure to $\mathrm{pHIV}_{\mathrm{NL4}-3}$ does not fully reflect HIV infection in vivo. The virus lacks viral enzymes reverse transcriptase and protease which are necessary to continue its replication cycle. We anticipate that the inductive effects of HIV on the transporters is most likely due to the viral proteins such as Tat and gp120. Hayashi et al. previously demonstrated that treatment of mouse brain microvascular endothelial cells with Tat induced the functional expression of P-gp through NF- $\kappa \mathrm{B}$ mediated mechanisms (Hayashi et al., 2005). Furthermore, Tat induced MRP1 expression and function in mouse brain microvascular endothelial cells and astrocytes following activation of the mitogen-activated protein kinase signaling cascade (Hayashi et al., 2006). In addition, an induction of the expression and function of BCRP was reported in Tat-expressing Jurkat T-cell lines compared to control cells (Zhou et al., 2016). While the $\mathrm{pHIV}_{\mathrm{NL4-3}}$ virus was pseudotyped with VSVG, we also demonstrated a potential role of gp120 in inducing T-cell activation and the expression of the transporters.

Overall, our results suggest that $\mathrm{pHIV}_{\mathrm{NL} 4-3}$ infection enhanced $\mathrm{T}$-cell activation, and increased the expression of $\mathrm{ABC}$ drug efflux transporters potentially through the mTOR signaling pathway. Our study sheds light on molecular pathways that could contribute to persistent HIV infection, but further work is needed to elucidate the mTOR downstream signaling processes governing the upregulation of these $A B C$ transporters, for example protein synthesis. HIV-induced activation of $\mathrm{T}$-cells could result in viral replication and inflammation (Prasad et al., 2019). Furthermore, ABC drug efflux transporters are induced following HIV infection, and could restrict ARV penetration in T-cell reservoirs (Janneh et al., 2005, 2007; Fletcher et al., 2014; Whyte-Allman et al., 2020), as well as potentially contribute to HIV-associated inflammation indirectly through the secretion of proinflammatory cytokines (Drach et al., 1996). Therefore, the involvement of these transporters must be considered when developing therapeutic strategies to control HIV-associated immune activation and inflammation, as well as for improving the efficacy of ARVs in viral reservoirs and sanctuary sites. 


\section{DATA AVAILABILITY STATEMENT}

The original contributions presented in the study are included in the article/Supplementary Material, further inquiries can be directed to the corresponding author.

\section{ETHICS STATEMENT}

The studies involving human participants were reviewed and approved by Unity Health Toronto Research Ethics Board, St. Michael's Hospital, 30 Bond St, Toronto, Ontario M5B 1W8, Canada. The patients/participants provided their written informed consent to participate in this study.

\section{AUTHOR CONTRIBUTIONS}

S-KW-A and RB participated in research design; S-KW-A conducted experiments; $\mathrm{RB}$ and $\mathrm{RK}$ contributed reagents or analytical tools; S-KW-A and RB performed data analysis; S-KW-A and RB wrote or contributed to the writing of the manuscript. All authors provided critical review of the manuscript and have given approval to the final version of the manuscript.

\section{REFERENCES}

Ashraf, T., Jiang, W., Hoque, M., Henderson, J., Wu, C., and Bendayan, R. (2014a). Role of Anti-inflammatory Compounds in Human Immunodeficiency Virus-1 Glycoprotein120-Mediated Brain Inflammation. J. Neuroinflammation 11, 91-14. doi:10.1186/1742-2094-11-91

Ashraf, T., Kao, A., and Bendayan, R. (2014b). Functional Expression of Drug Transporters in Glial Cells. Adv. Pharmacol. 71, 45-111. doi:10.1016/ bs.apha.2014.06.010

Benavides-Serrato, A., Lee, J., Holmes, B., Landon, K. A., Bashir, T., Jung, M. E., et al. (2017). Specific Blockade of Rictor-mTOR Association Inhibits mTORC2 Activity and Is Cytotoxic in Glioblastoma. PLoS One 12, e0176599-20. doi:10.1371/journal.pone.0176599

Bhagwat, S. V., Gokhale, P. C., Crew, A. P., Cooke, A., Yao, Y., Mantis, C., et al. (2011). Preclinical Characterization of OSI-027, a Potent and Selective Inhibitor of mTORC1 and mTORC2: Distinct from Rapamycin. Mol. Cancer Ther. 10, 1394-1406. doi:10.1158/1535-7163.MCT-10-1099

Biancotto, A., Iglehart, S. J., Vanpouille, C., Condack, C. E., Lisco, A., Ruecker, E., et al. (2008). HIV-1-induced Activation of CD4+ T Cells Creates New Targets for HIV-1 Infection in Human Lymphoid Tissue Ex Vivo, Blood, 111, 699-704. doi:10.1182/blood-2007-05-088435

Catalfamo, M., Wilhelm, C., Tcheung, L., Proschan, M., Friesen, T., Park, J.-H., et al. (2011). CD4 and CD8 T Cell Immune Activation during Chronic HIV Infection: Roles of Homeostasis, HIV, Type I IFN, and IL-7. J.I. 186, 2106-2116. doi:10.4049/jimmunol.1002000

Chen, B. W., Chen, W., Liang, H., Liu, H., Liang, C., Zhi, X., et al. (2015). Inhibition of mTORC2 Induces Cell-Cycle Arrest and Enhances the Cytotoxicity of Doxorubicin by Suppressing MDR1 Expression in HCC Cells. Mol. Cancer Ther. 14, 1805-1815. doi:10.1158/1535-7163.MCT-15-0029

Cummins, N. W., Rizza, S. A., and Badley, A. D. (2010). How Much Gp120 Is There?. J. Infect. Dis. 201, 1273-1274. doi:10.1086/65143310.1086/651434

Delgoffe, G. M., and Powell, J. D. (2009). MTOR: Taking Cues from the Immune Microenvironment. Immunology 127, 459-465. doi:10.1111/j.13652567.2009.03125.x

\section{FUNDING}

This work was supported by a University of Toronto internal grant (202074) awarded to RB.

\section{ACKNOWLEDGMENTS}

We would like to thank Alan Cochrane for kindly providing the plasmids to generate the $\mathrm{HIV}_{\mathrm{NL} 4-3}$-VSVG viral pseudotype. We also thank Julian Gilmore for his assistance with generation of the HIV $_{\text {NL4-3 }}$ viral pseudotype. We acknowledge the Centre of Pharmaceutical Oncology at the Leslie Dan Faculty of Pharmacy for the use of the flow cytometry equipment. RB is a career scientist of the Ontario HIV Treatment Network (OHTN). S-KW-A was the recipient of the University of Toronto Connaught International Scholarship for Doctoral Students, and a Mitacs Research Training Award.

\section{SUPPLEMENTARY MATERIAL}

The Supplementary Material for this article can be found online at: https://www.frontiersin.org/articles/10.3389/fphar.2021.711999/ full\#supplementary-material

Deng, J., Mitsuki, Y.-y., Shen, G., Ray, J. C., Cicala, C., Arthos, J., et al. (2016). HIV Envelope Gp120 Alters T Cell Receptor Mobilization in the Immunological Synapse of Uninfected CD4 T Cells and Augments T Cell Activation. J. Virol. 90, 10513-10526. doi:10.1128/JVI.01532-16

Doms, R. W., and Moore, J. P. (2010). HIV-1 Coreceptor Use: A Molecular Window into Viral Tropism. HIV Seq. Database. Available at:https://www.hiv. lanl.gov/content/sequence/HIV/REVIEWS/doms.html (Accessed January 26, 2021).

Drach, J., Gsur, A., Hamilton, G., Zhao, S., Angerler, J., Fiegl, M., et al. (1996). Involvement of P-Glycoprotein in the Transmembrane Transport of Interleukin-2 (IL-2), IL-4, and Interferon-Gamma in normal Human T Lymphocytes. Blood 88, 1747-1754. doi:10.1182/blood.v88.5.1747.1747

Ebert, C., Perner, F., Wolleschak, D., Schnoder, T., Fischer, T., and Heidel, H. (2016). Expression and Function of ABC-Transporter Protein ABCB1 Correlates with Inhibitory Capacity of Ruxolitinib In Vitro and In Vivo. Haematologica 101, 81-85. doi:10.3324/haematol.2015.136754

Fletcher, C. V., Staskus, K., Wietgrefe, S. W., Rothenberger, M., Reilly, C., Chipman, J. G., et al. (2014). Persistent HIV-1 Replication Is Associated with Lower Antiretroviral Drug Concentrations in Lymphatic Tissues. Proc. Natl. Acad. Sci. USA 111, 2307-2312. doi:10.1073/pnas.1318249111

Frank, M. H., Denton, M. D., Alexander, S. I., Khoury, S. J., Sayegh, M. H., and Briscoe, D. M. (2001). Specific MDR1 P-Glycoprotein Blockade Inhibits Human Alloimmune $\mathrm{T}$ Cell Activation In Vitro. J. Immunol. 166, 2451-2459. doi:10.4049/jimmunol.166.4.2451

Freeman, M. L., Shive, C. L., Nguyen, T. P., Younes, S.-A., Panigrahi, S., and Lederman, M. M. (2016). Cytokines and T-Cell Homeostasis in HIV Infection. J. Infect. Dis. 214, S51-S57. doi:10.1093/infdis/jiw287

Grivel, J.-C., Penn, M. L., Eckstein, D. A., Schramm, B., Speck, R. F., Abbey, N. W., et al. (2000). Human Immunodeficiency Virus Type 1 Coreceptor Preferences Determine Target T-Cell Depletion and Cellular Tropism in Human Lymphoid Tissue. J. Virol. 74, 5347-5351. doi:10.1128/jvi.74.11.5347-5351.2000

Gupta, S., and Gollapudi, S. (1993). P-glycoprotein (MDR 1 Gene Product) in Cells of the Immune System: its Possible Physiologic Role and Alteration in Aging and Human Immunodeficiency Virus-1 (HIV-1) Infection. J. Clin. Immunol. 13, 289-301. doi:10.1007/bf00920237 
Gupta, S., Kim, C. H., Tsuruo, T., and Gollapudi, S. (1992). Preferential Expression and Activity of Multidrug Resistance Gene 1 Product (P-Glycoprotein), a Functionally Active Efflux Pump, in Human CD8 + T Cells: A Role in Cytotoxic Effector Function. J. Clin. Immunol. 12, 451-458. doi:10.1007/ bf00918857

Hayashi, K., Pu, H., Andras, I. E., Eum, S. Y., Yamauchi, A., Hennig, B., et al. (2006). HIV-TAT Protein Upregulates Expression of Multidrug Resistance Protein 1 in the Blood-Brain Barrier. J. Cereb. Blood Flow Metab. 26, 1052-1065. doi:10.1038/sj.jcbfm.9600254

Hayashi, K., Pu, H., Tian, J., Andras, I. E., Lee, Y. W., Hennig, B., et al. (2005). HIVtat Protein Induces P-Glycoprotein Expression in Brain Microvascular Endothelial Cells. J. Neurochem. 93, 1231-1241. doi:10.1111/j.14714159.2005.03114.x

Herrero-Sánchez, M. C., Rodríguez-Serrano, C., Almeida, J., San Segundo, L., Inogés, S., Santos-Briz, Á., et al. (2016). Targeting of PI3K/AKT/mTOR Pathway to Inhibit $\mathrm{T}$ Cell Activation and Prevent Graft-Versus-Host Disease Development. J. Hematol. Oncol. 9, 1-14. doi:10.1186/s13045-0160343-5

Huang, Y. H., Schäfer-elinder, L., Wu, R., Claesson, H. E., and Frostegård, J. (1999). Lysophosphatidylcholine (LPC) Induces Proinflammatory Cytokines by a Platelet-Activating Factor (PAF) Receptor-dependent Mechanism. Clin. Exp. Immunol. 116, 326-331. doi:10.1046/j.1365-2249.1999.00871.x

Islam, S., Hoque, S. A., Adnan, N., Tanaka, A., Jinno-Oue, A., and Hoshino, H. (2013). X4-tropic Human Immunodeficiency Virus IIIB Utilizes CXCR4 as Coreceptor, as Distinct from R5X4-Tropic Viruses. Microbiol. Immunol. 57, 437-444. doi:10.1111/1348-0421.12051

Janneh, O., Jones, E., Chandler, B., Owen, A., and Khoo, S. H. (2007). Inhibition of P-Glycoprotein and Multidrug Resistance-Associated Proteins Modulates the Intracellular Concentration of Lopinavir in Cultured CD4 T Cells and Primary Human Lymphocytes. J. Antimicrob. Chemother. 60, 987-993. doi:10.1093/jac/ dkm353

Janneh, O., Owen, A., Chandler, B., Hartkoorn, R. C., Hart, C. A., Bray, P. G., et al. (2005). Modulation of the Intracellular Accumulation of Saquinavir in Peripheral Blood Mononuclear Cells by Inhibitors of MRP1, MRP2, P-Gp and BCRP. AIDS 19, 2097-2102. doi:10.1097/01.aids.0000194793.36175.40

Kedzierska, K., and Crowe, S. M. (2001). Cytokines and HIV-1: Interactions and Clinical Implications. Antivir. Chem. Chemother. 12, 133-150. doi:10.1177/ 095632020101200301

Köller, H., Schaal, H., Rosenbaum, C., Czardybon, M., Giesen, H. J. V., Müller, H. W., et al. (2002). Functional CXCR4 Receptor Development Parallels Sensitivity to HIV-1 Gp120 in Cultured Rat Astroglial Cells but Not in Cultured Rat Cortical Neurons. J. Neurovirol. 8, 411-419. doi:10.1080/ $1355028029010084210.1080 / 13550280260422712$

Kumar, B., Arora, S., Ahmed, S., and Banerjea, A. C. (2017). Hyperactivation of Mammalian Target of Rapamycin Complex 1 by HIV-1 Is Necessary for Virion Production and Latent Viral Reactivation. FASEB j. 31, 180-191. doi:10.1096/ fj.201600813R

Kuo, M. T., Liu, Z., Wei, Y., Lin-Lee, Y.-c., Tatebe, S., Mills, G. B., et al. (2002). Induction of Human MDR1 Gene Expression by 2-acetylaminofluorene Is Mediated by Effectors of the Phosphoinositide 3-kinase Pathway that Activate $\mathrm{NF}-\mathrm{Kb}$ Signaling. Oncogene 21, 1945-1954. doi:10.1038/sj/onc/ 120511710.1038/sj.onc.1205117

Kuo, T.-C., Chiang, P.-C., Yu, C.-C., Nakagawa-Goto, K., Bastow, K. F., Lee, K.-H., et al. (2011). A Unique P-Glycoprotein Interacting Agent Displays Anticancer Activity against Hepatocellular Carcinoma through Inhibition of GRP78 and mTOR Pathways. Biochem. Pharmacol. 81, 1136-1144. doi:10.1016/ j.bcp.2011.02.013

Lacy, P., and Stow, J. L. (2011). Cytokine Release from Innate Immune Cells: Association with Diverse Membrane Trafficking Pathways. Blood 118, 9-18. doi:10.1182/blood-2010-08-265892

Lee, C., Liu, Q.-H., Tomkowicz, B., Yi, Y., Freedman, B. D., and Collman, R. G. (2003). Macrophage Activation through CCR5- and CXCR4-Mediated Gp120Elicited Signaling Pathways. J. Leukoc. Biol. 74, 676-682. doi:10.1189/ jlb.0503206.1

Liptrott, N. J., Khoo, S. H., Back, D. J., and Owen, A. (2008). Detection of ABCC2, CYP2B6 and CYP3A4 in Human Peripheral Blood Mononuclear Cells Using Flow Cytometry. J. Immunological Methods 339, 270-274. doi:10.1016/ j.jim.2008.09.010
Maartens, G., Celum, C., and Lewin, S. R. (2014). HIV Infection: Epidemiology, Pathogenesis, Treatment, and Prevention. The Lancet 384, 258-271. doi:10.1016/S0140-6736(14)60164-1

Meier, A., and Altfeld, M. (2007). Toll-like Receptor Signaling in HIV-1 Infection: a Potential Target for Therapy?. Expert Rev. Anti-infective Ther. 5, 323-326. doi:10.1586/14787210.5.3.323

Minuesa, G., Arimany-nardi, C., Erkizia, I., Cedeño, S., Moltó, J., Clotet, B., et al. (2016). P-glycoprotein (ABCB1) Activity Decreases Raltegravir Disposition in Primary CD4+P-Gphighcells and Correlates with HIV-1 Viral Load. J. Antimicrob. Chemother. 71, 2782-2792. doi:10.1093/jac/dkw215

Nickel, W. (2003). The Mystery of Nonclassical Protein Secretion. Eur. J. Biochem. 270, 2109-2119. doi:10.1046/j.1432-1033.2003.03577.x

O'Doherty, U., Swiggard, W. J., and Malim, M. H. (2000). Human Immunodeficiency Virus Type 1 Spinoculation Enhances Infection through Virus Binding. J. Virol. 74, 10074-10080. doi:10.1128/jvi.74.21.1007410080.2000

Omeragic, A., Hoque, M. T., Choi, U.-y., and Bendayan, R. (2017). Peroxisome Proliferator-Activated Receptor-Gamma: Potential Molecular Therapeutic Target for HIV-1-Associated Brain Inflammation. J. Neuroinflammation 14, 1-13. doi:10.1186/s12974-017-0957-8

Omeragic, A., Kara-Yacoubian, N., Kelschenbach, J., Sahin, C., Cummins, C. L., Volsky, D. J., et al. (2019). Peroxisome Proliferator-Activated Receptor-Gamma Agonists Exhibit Anti-inflammatory and Antiviral Effects in an EcoHIV Mouse Model. Sci. Rep. 9, 1-12. doi:10.1038/s41598-019-45878-6

Omeragic, A., Saikali, M. F., Currier, S., Volsky, D. J., Cummins, C. L., and Bendayan, R. (2020). Selective Peroxisome Proliferator-activated Receptorgamma Modulator, INT131 Exhibits Anti-inflammatory Effects in an EcoHIV Mouse Model. FASEB j. 34, 1996-2010. doi:10.1096/fj.201901874R

Pawlik, A., Gawrońska-Szklarz, B., Baśkiewicz-Masiuk, M., Machaliński, B., and Safranow, K. (2010). Involvement of P-Glycoprotein in the Release of Cytokines from Peripheral Blood Mononuclear Cells Treated with Methotrexate and Dexamethasone. J. Pharm. Pharmacol. 57, 1421-1425. doi:10.1211/jpp.57.11.0007

Platt, C., Calimano, M., Nemet, J., Bubenik, J., and Cochrane, A. (2015). Differential Effects of Tra2ß Isoforms on HIV-1 RNA Processing and Expression. PLoS One 10, e0125315-21. doi:10.1371/journal.pone.0125315

Pop, I. V., Pop, L. M., Ghetie, M.-A., and Vitetta, E. S. (2009). Targeting Mammalian Target of Rapamycin to Both Downregulate and Disable the P-Glycoprotein Pump in Multidrug-Resistant B-Cell Lymphoma Cell Lines. Leuk. Lymphoma 50, 1155-1162. doi:10.1080/10428190903046722

Prasad, A., Kulkarni, R., Shrivastava, A., Jiang, S., Lawson, K., and Groopman, J. E. (2019). Methamphetamine Functions as a Novel CD4+ T-Cell Activator via the Sigma-1 Receptor to Enhance HIV-1 Infection. Sci. Rep. 9, 1-13. doi:10.1038/ s41598-018-35757-x

Raggers, R. J., Vogels, I., and van Meer, G. (2001). Multidrug-resistance P-Glycoprotein (MDR1) Secretes Platelet-Activating Factor. Biochem. J. 357, 859-865. doi:10.1042/0264-6021:3570859

Ronaldson, P. T., Ashraf, T., and Bendayan, R. (2010). Regulation of Multidrug Resistance Protein 1 by Tumor Necrosis Factor $a$ in Cultured Glial Cells: Involvement of Nuclear Factor-Kb and C-Jun N-Terminal Kinase Signaling Pathways. Mol. Pharmacol. 77, 644-659. doi:10.1124/mol.109.059410

Ronaldson, P. T., and Bendayan, R. (2008). HIV-1 Viral Envelope Glycoprotein Gp120 Produces Oxidative Stress and Regulates the Functional Expression of Multidrug Resistance Protein-1 (Mrp1) in Glial Cells. J. Neurochem. 106, 1298-1313. doi:10.1111/j.1471-4159.2008.05479.x

Ronaldson, P. T., and Bendayan, R. (2006). HIV-1 Viral Envelope Glycoprotein Gp120 Triggers an Inflammatory Response in Cultured Rat Astrocytes and Regulates the Functional Expression of P-Glycoprotein. Mol. Pharmacol. 70, 1087-1098. doi:10.1124/mol.106.025973.perivascular

Scherbakova, E. A., Rybalkina, E. Y., Stromskaya, T. P., and Stavrovskaya, A. A. (2009). Participation of mTOR in the Regulation of Multidrug Resistance of Tumor Cells. Biochem. Mosc. Suppl. Ser. A 3, 184-189. doi:10.1134/ S1990747809020111

Turriziani, O., Gianotti, N., Falasca, F., Boni, A., Vestri, A. R., Zoccoli, A., et al. (2008). Expression Levels of MDR1, MRP1, MRP4, and MRP5 in Peripheral Blood Mononuclear Cells from HIV Infected Patients Failing Antiretroviral Therapy. J. Med. Virol. 80, 766-771. doi:10.1002/jmv10.1002/jmv.21152

van de Ven, R., Oerlemans, R., van der Heijden, J. W., Scheffer, G. L., de Gruijl, T. D., Jansen, G., et al. (2009). ABC Drug Transporters and Immunity: Novel 
Therapeutic Targets in Autoimmunity and Cancer. J. Leukoc. Biol. 86, 1075-1087. doi:10.1189/jlb.0309147

Wang, S.-F., Chou, Y.-C., Mazumder, N., Kao, F.-J., Nagy, L. D., Guengerich, F. P., et al. (2013). 7-Ketocholesterol Induces P-Glycoprotein through PI3K/mTOR Signaling in Hepatoma Cells. Biochem. Pharmacol. 86, 548-560. doi:10.1016/ j.bcp.2013.06.006

Wei, W.-C., Liu, C.-P., Yang, W.-C., Shyur, L.-F., Sheu, J.-H., Chen, S.-S., et al. (2015). Mammalian Target of Rapamycin Complex 2 (mTORC2) Regulates LPS-Induced Expression of IL-12 and IL-23 in Human Dendritic Cells. J. Leukoc. Biol. 97, 1071-1080. doi:10.1189/jlb.2a0414-206rr

Whyte-Allman, S.-K., Hoque, M. T., Gilmore, J. C., Kaul, R., Routy, J.-P., and Bendayan, R. (2020). Drug Efflux Transporters and Metabolic Enzymes in Human Circulating and Testicular T-Cell Subsets: Relevance to HIV Pharmacotherapy. AIDS 34, 1439-1449. doi:10.1097/QAD.0000000000002548

Whyte-Allman, S.-K., Hoque, M. T., Jenabian, M.-A., Routy, J.-P., and Bendayan, R. (2017). Xenobiotic Nuclear Receptors Pregnane X Receptor and Constitutive Androstane Receptor Regulate Antiretroviral Drug Efflux Transporters at the Blood-Testis Barrier. J. Pharmacol. Exp. Ther. 363, 324-335. doi:10.1124/ jpet.117.243584

Woodham, A. W., Skeate, J. G., Sanna, A. M., Taylor, J. R., Da Silva, D. M., Cannon, P. M., et al. (2016). Human Immunodeficiency Virus Immune Cell Receptors, Coreceptors, and Cofactors: Implications for Prevention and Treatment. AIDS Patient Care and STDs 30, 291-306. doi:10.1089/apc.2016.0100

Zhang, J.-C., Deng, Z.-Y., Wang, Y., Xie, F., Sun, L., and Zhang, F.-X. (2014). Expression of Breast Cancer Resistance Protein in Peripheral T Cell Subsets from HIV-1-Infected Patients with Antiretroviral Therapy. Mol. Med. Rep. 10, 939-946. doi:10.3892/mmr.2014.2282
Zhang, J., Alston, M. A., Huang, H., and Rabin, R. L. (2006). Human T Cell Cytokine Responses Are Dependent on Multidrug Resistance Protein-1. Interntional Immunol. 18, 485-493. doi:10.1093/intimm/dxh389

Zhou, Y., Zhang, K., Yin, X., Nie, Q., and Ma, Y. (2016). HIV-1 Tat Protein Enhances Expression and Function of Breast Cancer Resistance Protein. AIDS Res. Hum. Retroviruses 32, 1-3. doi:10.1089/aid.2015.0117

Zimmermann, K., Liechti, T., Haas, A., Rehr, M., Trkola, A., Günthard, H. F., et al. (2015). The Orientation of HIV-1 Gp120 Binding to the CD4 Receptor Differentially Modulates CD4+T Cell Activation. J.I. 194, 637-649. doi:10.4049/jimmunol.1401863

Conflict of Interest: The authors declare that the research was conducted in the absence of any commercial or financial relationships that could be construed as a potential conflict of interest.

Publisher's Note: All claims expressed in this article are solely those of the authors and do not necessarily represent those of their affiliated organizations, or those of the publisher, the editors and the reviewers. Any product that may be evaluated in this article, or claim that may be made by its manufacturer, is not guaranteed or endorsed by the publisher.

Copyright (C) 2021 Whyte-Allman, Kaul and Bendayan. This is an open-access article distributed under the terms of the Creative Commons Attribution License (CC BY). The use, distribution or reproduction in other forums is permitted, provided the original author(s) and the copyright owner(s) are credited and that the original publication in this journal is cited, in accordance with accepted academic practice. No use, distribution or reproduction is permitted which does not comply with these terms. 